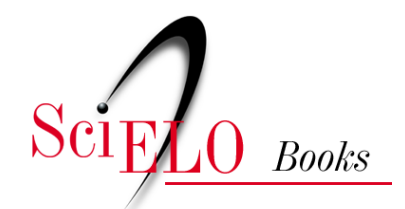

\title{
Abertura \\ Movimentos sociais, institucionalização e domínios de agência
}

\author{
Adrian Gurza Lavalle \\ Euzeneia Carlos \\ Monika Dowbor \\ José Szwako
}

LAVALLE, A.G., CARLOS, E., DOWBOR, M., and SZWAKO, J., comps. Abertura - Movimentos sociais, institucionalização e domínios de agência. In: Movimentos sociais e institucionalização: políticas sociais, raça e gênero no Brasil pós-transição [online]. Rio de Janeiro: EDUERJ, 2018, pp. 20-86. Sociedade e política collection. ISBN: 978-85-7511-479-7. https://doi.org/10.7476/9788575114797.0003.

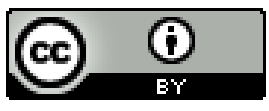

All the contents of this work, except where otherwise noted, is licensed under a Creative Commons Attribution 4.0 International license.

Todo o conteúdo deste trabalho, exceto quando houver ressalva, é publicado sob a licença Creative Commons Atribição 4.0.

Todo el contenido de esta obra, excepto donde se indique lo contrario, está bajo licencia de la licencia $\underline{\text { Creative }}$ Commons Reconocimento 4.0 . 
ABERTURA 


\title{
Movimentos Sociais,
}

\author{
INSTITUCIONALIZAÇÃO E
}

DOMÍNIOS DE AGÊNCIA

\author{
Adrian Gurza Lavalle ${ }^{1}$ \\ Euzeneia Carlos \\ Monika Dowbor \\ José Szwako
}

\section{Introdução ${ }^{2}$}

A institucionalização pública estatal de formas de controle e incidência social sobre políticas públicas e de instâncias de participação, agendas oriundas da sociedade civil, bem como das categorias nativas que sintetizam o sentido dessas agendas, ordenando as práticas dos atores sociais, é fenômeno dos mais notáveis do Brasil pós-transição e, no entanto, jaz na penumbra deitada pelas prin-

1 Os autores agradecem o apoio do Centro de Estudos da Metrópole (Cepid-CEM), financiado pela Fundação de Amparo à Pesquisa do Estado de São Paulo (Fapesp), processo n ${ }^{\circ}$ 2013/07616-7. As opiniốes, hipóteses e conclusões ou recomendaçốes expressas são de responsabilidade dos autores e não necessariamente refletem a visão da Fapesp.

2 Versões preliminares deste trabalho foram apresentadas em sessões especiais no Congresso Nacional de Ciências Sociais, Universidade Federal de Espírito Santo (Conacso/Ufes, setembro 2015) e no III Encontro Internacional Participação Democracia e Políticas Públicas (III PDPP/Ufes, maio 2017). Agradecemos os comentários certeiros de Marisa von Bülow e Rebecca Abers, debatedoras de nosso trabalho, respectivamente, em cada um desses eventos. Também somos gratos e gratas aos membros do Núcleo Democracia e Ação Coletiva (NDAC) pela intensa interlocução ao longo de numerosas sessões discutindo a abordagem de domínios de agência. A responsabilidades por falhas persistentes é, evidentemente, apenas nossa. 
cipais literaturas que, em princípio, estariam orientadas a iluminá-lo. A relação entre "o poder social", ou a organização coletiva de interesses e valores, e "o Estado", ou as instituições políticas e da administração pública, tem sido objeto de teorização - quer em registro realista ou normativo - por três corpos teóricos influentes: pluralismo, neocorporativismo e teorias dos movimentos sociais. Por motivos a serem explorados ao longo destas páginas, pressupostos analíticos cruciais desses corpos teóricos ora eclipsam os processos de institucionalização, ora reduzem sua diversidade e induzem leituras peculiarmente restritivas dos mesmos. Essas lentes, argumenta-se, não permitem apreender a especificidade dos padrões de interação socioestatais que contribuíram decisivamente, no país, para moldar a atuação setorial do Estado - em saúde ou assistência social, para mencionar apenas dois exemplos emblemáticos abordados neste livro - ou o desenho de políticas mais específicas - o campo da saúde para a população negra ou a política de HIV, para permanecer em casos do terreno da saúde também examinados nestas páginas. Tampouco contribuem, na direção inversa, para compreender a atuação dos movimentos sociais (doravante MSs) ou das organizações da sociedade civil (doravante OSCs) e sua capacidade de incidência sobre as políticas sociais no contexto da pós-transição.

Repare-se, o fenômeno notável que ocupa as páginas deste trabalho é a "institucionalização" e não as "instituições". Enquanto o segundo termo pressupóe a fixidez de atributos e permanência temporal daquilo que é, o primeiro opera como um verbo substantivado e remete ao devir, mais especificamente ao processo de institucionalizar, de transformação de algo em instituição. É a transformação em instituições de valores, interesses, demandas e recursos de atuação de MSs e OSCs atuando em nome de grupos marginalizados e agendas tradicionalmente periféricas ao sistema político que se impôs como novidade histórica demandando explicação àqueles que estudam movimentos sociais. Assim, ocupar-se 
da institucionalização no Brasil pós-transição não apenas dista de ser fortuito, como oferece uma perspectiva privilegiada de interrogação da literatura pluralista, neocorporativa e de movimentos sociais que evidencia suas lacunas. Certamente a institucionalização não é fenômeno exclusivo da pós-transição nem, é claro, da história nacional: outros atores historicamente posicionados em condições favoráveis para imprimir seus interesses nas decisões de autoridades públicas, notadamente atores de mercado e/ou corporativos, receberam atenção das literaturas pluralista e neocorporativa. Em boa medida, essas literaturas desenvolveram-se analiticamente graças ao foco naqueles atores e na política de defesa de seus interesses. Entretanto, a novidade histórica dos anos da pós-transição no país tornou pertinente desenvolver perspectivas analíticas para lidar com a institucionalização em relação a uma constelação de atores tradicionalmente pensados em registro de contestação e para os quais - conforme será mostrado - os registros analíticos predominantes resultam insatisfatórios. Mais: as lacunas detectadas sob o prisma dos processos de institucionalização que aqui interessam permitem projetar implicações analíticas gerais, e não apenas para determinado conjunto de atores em determinado tempo ou espaço.

Para apreender os processos de institucionalização, o neo-institucionalismo histórico, sensível ao estatuto causal dos processos temporais - sequências, trajetórias, cadeias causais, dependência da trajetória (Mahoney, 1999, 2000) -, oferece registro analítico que permite assumir o caráter mutuamente constitutivo das relações entre Estado e sociedade civil. Nesse sentido, constitui perspectiva especialmente oportuna para examinar e entender os processos de institucionalização de interesses, valores e agendas sociais e de constituição de capacidades estatais como produto de interações socioestatais. A intuição básica quanto ao caráter constitutivo dessas interações não é novidade e é possível encontrá-la em pleno funcionamento no trabalho espantosamente lúcido de 
Peter Nettl (1968) sobre o Partido Social-Democrata Alemão (1890-1914) como modelo político. Isto é, duas décadas antes da obra coletiva seminal de Evans, Rueshermeyer e Skocpol (1985) dedicada a trazer o Estado de volta; obra não raro referida como certidão de nascimento da primeira geração do neo-institucionalismo histórico. Não é gratuito que Nettl seja referência constante nessa obra.

Nos trabalhos dessa geração de neo-institucionalistas históricos, a interpenetração entre Estado e sociedade civil foi alçada ao plano da teoria e dos conceitos. Da perspectiva dos atores sociais, a proposta seminal foi de Theda Skocpol (1992). Denominada por ela de polity approach - abordagem do corpo político ou da polis, em tradução aproximada -, centrou nos processos de interação socioestatais que permitiam aos atores sociais ora se adequar favoravelmente ao - e tirar vantagens para a mobilização do - contexto institucional maior, ora "cavar espaços ou entradas" ou, mais propriamente, arquitetar encaixes institucionais no Estado (engineering fit). Assim, em Skocpol o conceito encaixe (fit) outorgou concreção institucional aos resultados das interações socioestatais. Isto porque, se sob determinadas circunstâncias, os processos de interação permitiam aos atores sociais arquitetar encaixes no Estado - pontos de acesso (points of access), órgãos, regras, prioridades, leis -, a seletividade intrínseca às instituições passaria a funcionar favorecendo esses atores tornando o Estado continuamente poroso aos seus interesses e valores.

E mais: além e ao lado da noção de encaixes institucionais, o neo-institucionalismo histórico legou ainda o foco de análise nas capacidades estatais. Se nas suas primeiras formulações, a produção de C. Tilly (1975) e T. Skocpol (1979) estava atenta a macroprocessos de State building, aos graus de controle (ou descontrole) sobre partes da população e do território, a agenda da década seguinte enfatizou as capacidades estatais como traço distintivo da autonomia do Estado. A inflexão dessa agenda enfática quanto 
à autonomia do Estado, prévia ao polity-approach, inspira nossa agenda de pesquisa porquanto aponta para a permanência e pertinência analíticas das capacidades estatais como dimensão central na compreensão da institucionalização das demandas e interesses dos MSs e OSCs vis-á-vis o Estado. Assim, a agenda centrada na institucionalização pode observar o fenômeno quer da perspectiva dos atores sociais quer da perspectiva dos atores estatais, sem abrir mão de uma abordagem processual que assume o caráter mutuamente constitutivo das relações entre Estado e sociedade civil. Dado nosso interesse nos MSs e OSCs, a primeira perspectiva recebe maior tratamento analítico nestas páginas, mas a segunda também é abordada.

Aquelas ideias e conceitos seminais aventados por Skocpol, todavia, permaneceram subteorizados. Argumenta-se aqui que as distinções analíticas pioneiras cunhadas pelo neo-institucionalismo histórico carecem de especificação sistemática quanto à sua variabilidade empírica em três dimensões: (i) os tipos de encaixes institucionais e suas especificidades ou variação horizontal; (ii) a hierarquia política ou variação vertical em que operam encaixes e, por fim, (iii) a articulação entre diversos encaixes posicionados em níveis distintos de hierarquia política, isto é, suas configuraçôes. Quanto à variação horizontal dos tipos de encaixes, há diversas formas em que o Estado e a administração pública tornam-se porosos aos interesses sociais mediante expedientes que comportam graus diversos de institucionalização. Ter o acesso franqueado para dialogar regularmente com um funcionário público chave, ocupar cargos, determinar uma regra, definir uma função institucional, criar um órgão incumbido de certos propósitos - inclusive garantir a participação de determinados segmentos da população - ou aprovar uma lei, para mencionar apenas alguns exemplos, constituem formas consideravelmente diversas de ativar favoravelmente a seletividade das instituições, e embora todas elas possam ser concebidas analiticamente como encaixes, suas implicações são 
distintas. A variabilidade em questão é horizontal porque desconsidera a posição específica da inserção dos encaixes no arcabouço institucional. Por isso as distinções analíticas pertinentes não remetem apenas à diversidade das feições desses encaixes, mas ao fato de os encaixes - inclusive os "mesmos" encaixes - poderem operar em níveis diferentes de autoridade. É a variação vertical ou, lançando mão de metáfora topográfica, "altitude" política que remete à hierarquia e permite atentar para a durabilidade dos encaixes e sua capacidade de subordinar instâncias inferiores à seletividade por eles introduzida, reduzindo a contingência dos interesses beneficiados por tais encaixes. Assim, sem levar em consideração a disposição horizontal e vertical dos encaixes, torna-se difícil apreciar a diferença entre uma coleção de encaixes avulsos e sua articulação em configurações de maior estabilidade, alcance e potência.

A abordagem aqui desenvolvida atenta, precisamente, para processos de institucionalização que geraram configurações de encaixes de alcance médio, situadas além de encaixes pontuais ou relativamente desarticulados e tendencialmente instáveis, e aquém das cristalizações institucionais de alto alcance e feições quase pétreas descritas pela literatura neocorporativa. Configurações de encaixes derivadas de processos de interação socioestatal, institucionalmente cristalizadas em níveis de hierarquia intermediários constituem dominios de agência, cujas propriedades distintivas definem a capacidade de ação dos atores aos que se reconhece agência em um âmbito de atuação específico. Como domínios de agência não nascem prontos, mas são produto de histórias de conflito, aprendizagem e cooperação, eles possuem perfis distintos; isto é, cada domínio responde a uma articulação de elementos produzidos em diferentes momentos: regulações, repertórios de atuação considerados legítimos e capacidades de ação dos atores sociais e do Estado. No plano empírico, estudos em profundidade constituem uma escolha propícia à identificação desses elementos; antes, obviamente, é mister delimitar os conceitos e suas relações, bem 
como aquilo que se entende por institucionalização e seu alcance. Essa tarefa receberá atenção nas páginas que se seguem.

Assim, após a formulação geral da questão nos termos expostos acima, o desafio está posto: iluminar ou retirar analiticamente da penumbra um conjunto de processos de institucionalização especialmente relevantes para o diagnóstico das transformações nas relações entre o Estado e os movimentos sociais no Brasil pós-transição. Com o intuito de avançar nessa direção, o objetivo deste capítulo introdutório é triplo: primeiro, examinar criticamente as abordagens disponíveis na literatura para se entender processos de institucionalização de interesses, valores e recursos de atuação de atores sociais de modo a evidenciar suas contribuições e limitações; segundo, desenvolver e mostrar os ganhos cognitivos de uma proposta de abordagem - a do dominio de agência - orientada pelo pressuposto da mútua constituição, radicalmente relacional e centrada em processos de institucionalização de alcance médio. Terceiro, e em consonância com esse pressuposto, estender os ganhos cognitivos para o Estado, argumentando o caráter reciprocamente determinante entre capacidades estatais e interações socioestatais: a capacidade acumulada (assim como a falta dela) modela, por via de configurações de encaixes e interações (indireta ou diretamente), as formas e estratégias pelas quais atores não estatais interpelam o Estado, assim como os instrumentos estatais de ação e intervenção são incrementados, entre outros fatores, pelo arco das interações travadas com MSs e OSCs - diremos: esses instrumentos têm gênese sociopolítica.

Por fim, e no intuito de evitar mal-entendidos, cabe reiterar: é a dissonância entre as expectativas analíticas geradas pelas teorias disponíveis e as características distintivas dos domínios de agência emergidos no país no contexto do pós-transição que tem animado não apenas esta proposta, mas um movimento mais geral da literatura nacional de revisão de pressupostos teóricos e 
inovação conceitual. ${ }^{3}$ Embora as motivações derivem de preocupações contextuais - o cenário do Brasil pós-transição -, entendemos que toda preocupação é em maior ou menor medida contextual e que, por isso, sua relevância supõe o esforço de explicitar suas implicações de caráter geral. Isto é, uma abordagem teórica sobre os processos de institucionalização que definem as relações entre o Estado, os movimentos sociais e a sociedade civil não é, evidentemente, uma teoria sobre o Brasil, mas tornou-se pertinente porque informada pela experiência histórica do país. Conforme apontado, trata-se de processos carregados de significação teórica porque revelam aquilo que escapa aos arcabouços conceituais que utilizamos para pensar o mundo e, também, porque trazem à tona um conjunto de fenômenos que quiçá passaram despercebidos em outros contextos. Assim, a perspectiva de encaixes e domínios de agência aqui desenvolvida permite diagnosticar os processos empíricos de institucionalização ocorridos no pós-transição - notadamente sob as administrações do Partido da Social Democracia Brasileira e do Partido dos Trabalhadores -, mas a perspectiva analítica não se confunde com uma tese histórica e preserva seus conceitos e indagações básicas para contextos de governos com orientações partidárias e ideológicas as mais díspares - inclusive de cunho regressivo, como o que seguiu ao impeachment da presidente Dilma Rousseff. As configurações mudam conforme a coalizão governante, cedendo passo a outros atores e outros encaixes inscritos em diversos níveis de autoridade. Isso não significa que as configurações de encaixes e a operação de domínios de agência sejam menos relevantes, mas apenas que são outros os atores a serem analisados e outras também as redes transversais ao Estado em que esses atores disputam as decisões das autoridades públicas e constroem políticas. Nada mais, porém, nada menos. Restam as questões analíticas de fundo, mas não é possível derivar respostas

3 Para um balanço desse movimento ver Gurza Lavalle e Szwako (2015). 
dedutivamente; antes, os diagnósticos dependem do esforço coletivo da pesquisa empírica.

$\mathrm{O}$ arco da argumentação contempla vários passos: as seguintes duas seções estabelecem interlocução com a literatura com o intuito de mostrar os efeitos de ocultação por ela gerados sobre os processos de institucionalização que aqui interessam; depois, abordamos a proposta dos domínios de agência em diálogo com os desdobramentos mais recentes do neo-institucionalismo histórico e explicitamos sua adequação para apreender tais processos de institucionalização; por fim, à luz da trajetória ocupada pela noção de capacidades estatais no neo-institucionalismo, argumentamos que ela é noção heurística duplamente fértil, seja para iluminar as formas pelas quais o Estado molda as chances de acesso e resultados dos MSs e das OSCs, seja para compreender em que medida, por meio de quais instrumentos e interações, atores não estatais podem incrementar as capacidades do Estado. A última seção oferecerá uma síntese completa dos capítulos que integram o livro.

\section{O poder social e a institucionalização de interesses}

O pluralismo é uma teoria realista da organização do poder social ou da organização coletiva de interesses e valores e sua relação com as instituições incumbidas de tomar e implementar decisões vinculantes em sociedades com regimes democráticos. Embora existam discordâncias a respeito da presença de compreensões pluralistas originais e de orientação radical - deslocadas pelo pluralismo do segundo pós-guerra - ou, nas últimas décadas, pluralistas culturais, as quais obstariam compreensões unitárias ou de linhagem única do próprio pluralismo, parece incontroverso que aquela sintetizada na primeira frase deste parágrafo é de longe a versão mais conhecida do pluralismo e aquela que ocupa, na ciência política, a posição de compreensão mais influente da relação entre poder social e instituições políticas 
democráticas (Schlosberg, 1998). Pelo menos desde o famoso Prefácio à teoria democrática de Robert Dahl (1956), restou assente que as democracias garantem a presença dos interesses sociais tanto na formação de governos mediante as eleições quanto na tomada de decisões sobre políticas entre eleições e mediante processos em maior ou menor medida regulados de influência sobre o governo - manifestações, opinião pública, lobby (Truman, 1951; Dahl, 1961). Em sociedades complexas, diferenciadas e de mercado, tipicamente correlacionadas com regimes democráticos, não existiria um centro dominante de poder, mas um policentrismo expresso por excelência no pluralismo organizacional próprio dessas sociedades (Dahl, 1991). Interesses organizados - "associações", na linguagem pluralista - buscariam defender suas posições e fazer avançar suas prioridades nas decisões em que, eventualmente, resultariam afetados. As democracias pluralistas são, assim, regimes em que a disputa pela organização de poder social e sua influência sobre as autoridades ou poder público é lícita. A compreensão é realista porque centrada em interesses particulares, mesmo que coletivos, e porque as decisóes das autoridades exprimem o resultado dessa disputa (Marques, 1997).

O pluralismo não permite assimilar em seu arcabouço analítico a institucionalização da capacidade de ação de atores sociais no Estado, embora privilegie o conflito pela influência do poder social sobre as autoridades. De um lado, a ação do Estado apenas é compreensível se levadas em consideração as pressões sociais sobre ele - em linguagem alheia ao pluralismo, as interações socioestatais -, de outro, o próprio Estado é uma arena de disputa, munido de recursos controlados por burocracias com prioridades e interesses próprios, não coincidentes com essa ou aquela expressão do poder social. Assim, o Estado toma decisões que favorecem determinados interesses, em detrimento de outros, como resultado da disputa pluralista entre atores, e não porque privilegie sempre os mesmos atores. Por outras palavras, há predomínio de interesses particulares, 
mas não é invariável e, por isso, não constitui dominação, pois as associações beneficiadas pelas decisões públicas variam conforme a área da decisão e conforme a disputa da vez (Dahl, 1991). ${ }^{4}$ A perspectiva pluralista ilumina as causas que determinam decisões públicas, algumas das quais supõem a institucionalização de interesses dos atores vencedores em detrimento daqueles derrotados. Emblematicamente, leis são aprovadas porque, após barganha, negociação e pressão social, certos interesses se impõem sobre outros. Contudo, tal institucionalização diz respeito aos resultados ou benefícios das decisões públicas e não à capacidade da atuação em face do ou dentro do Estado. Processos de institucionalização que garantem o acesso permanente de certos interesses às instâncias de tomadas de decisão outorgariam a eles vantagens contínuas, envergando o funcionamento do Estado sistematicamente ou definindo permanentemente a seletividade das instituições em favor de certos grupos. Isso comprometeria o caráter do Estado como arena em disputa e ameaçaria introduzir distorções permanentes indesejáveis - dominação até - com efeitos corrosivos sobre a pluralidade de interesses organizados, e, por conseguinte, sobre os pressupostos analíticos do pluralismo.

A limitação recém-assinalada dista de ser original: a crítica mais contundente ao pluralismo pela incapacidade de oferecer uma leitura razoável da institucionalização de interesses nas sociedades democráticas remonta aos anos 1970 e veio da literatura neocorporativa. Mais: a literatura neocorporativa demarcou suas diferenças distintivas em relação ao pluralismo e à ambição de oferecer uma proposta analítica alternativa e realista do funcionamento das democracias nos contextos do segundo pós-guerra (Schmitter, 1974). Por sinal, fora do campo da teoria democrática também houve críticas que apontaram à especificidade das dinâmicas insti-

Tal formulação é uma resposta às críticas dirigidas contra o pluralismo pelo marxismo (Manley, 1983). 
tucionais do Estado e, em especial, da operação de políticas públicas: comunidades e redes de políticas, ou coligações reformistas ou de advocacy, para mencionar apenas alguns avanços nesse campo de estudos, implicam conformações socioestatais em maior ou menor medida estáveis de atores e interesses na definição de políticas (Knoke, 1996; Sabatier, 2007; Sabatier e Weible, 2007; Kingdom, 1995). O foco da literatura neocorporativista nas estruturas de intermediação de interesses, cuja expressão por excelência foram as instâncias nacionais de negociação tripartite entre Estado, sindicatos (trabalho) e federações de empregadores da indústria (capital), acarretou implicações corrosivas para o pluralismo, pois tais estruturas constituíam uma verdadeira anomalia para essa abordagem e, no entanto, multiplicaram-se como um expediente de negociação do conflito social em larga escala nas democracias avançadas. No diagnóstico da literatura neocorporativa, além de o pluralismo se revelar inacurado no terreno empírico e deficiente no plano teórico, trazia consigo consequências normativas indesejáveis, pois o pluralismo organizacional enfraquecia a capacidade de representação e negociação dos atores sociais em face do Estado e do poder econômico. Assim, sacrificar a pluralidade de vozes para alcançar a capacidade de "falar mais alto" era entendida como a escolha correta. Nas palavras incisivas de P. Schmitter: "as associações pluralistas enfraquecem o papel dos intermediários de interesses; as corporativistas o fortalecem" (1992, p. 439; Schmitter, 1974, pp. 97-109).

A literatura corporativa e, em particular, Schmitter em seus textos seminais sobre o corporativismo no século XX e a representação de interesse de grupos nos contextos de pós-transição democrática, iluminaram uma dupla dinâmica na institucionalização de estruturas de intermediação de interesses entre o Estado e atores sociais relevantes. Primeiro, a institucionalização para o e no Estado reconhecia e concedia capacidade de representação a atores sociais e assegurava essa capacidade concedendo-lhes o 
monopólio de representação de interesses sociais de grupos amplos, o acesso a recursos estáveis e o controle de barreiras de entrada para dificultar a emergência de concorrência na representação de tais interesses, garantindo, precisamente, o monopólio. Esse é emblematicamente o caso das centrais sindicais no mundo do trabalho e dos mecanismos institucionais a elas vinculados em combinações diferentes conforme o contexto nacional: filiação compulsória, taxas ou cotizações descontadas diretamente no hollerith (imposto sindical), representação sindical única por local de trabalho e por setor, representação reconhecida pelo Estado e pelas entidades patronais nas negociações salariais e de outros benefícios e condições de trabalho. A mesma caracterização pode ser aplicada a partidos políticos, investidos do monopólio de representação e assegurados por diversos direitos e benefícios nas arenas eleitoral e parlamentar do governo representativo. Graças a sua presença nas estruturas de intermediação de interesses como o parlamento, partidos adquirem poder de incidência direta sobre a alocação de recursos públicos e sobre a definição de diretrizes da ação do Estado, bem como capacidade de proteger seus interesses - assumindo que coincidem em algum grau com aqueles dos segmentos sociais em nome dos quais falam - e de impor perdas a outros grupos sociais. Assim, a institucionalização para o e no Estado a um só tempo constitui e constrange a capacidade de ação do próprio Estado, impregnando-a com um viés sistemático em favor dos atores representados.

A segunda dinâmica de institucionalização é na direção dos atores sociais, aquilo que Schmitter chamara de propriedades emergentes derivadas de tal institucionalização. Em troca da influência adquirida graças à institucionalização, atores sociais cedem controle ao Estado que, mediante legislação, regula-os definindo o alcance da representação, fontes lícitas e ilícitas de financiamento, atividades permitidas e interditadas, e feições básicas da organização interna. Sindicatos e partidos, por exemplo, exercem monopólio da representação restrito a determinada esfera da vida 
social, os primeiros não podem financiar os segundos e estes são proibidos de receber recursos oriundos de outros governos e organizações estrangeiras; direções sindicais precisam ser eleitas, diferentemente das partidárias, e os partidos precisam de estatuto e programa definidos conforme às disposições da lei correspondente. Em suma, para dizê-lo com a conhecida fórmula de Claus Offe (1998, pp. 225-268), a concessão ou atribuição de status público a um conjunto de atores sociais amplia sua capacidade de ação e, a um só tempo, supõe a intervenção reguladora do Estado.

A institucionalização não apenas constitui foco privilegiado da literatura neocorporativista, mas ganha densidade analítica mediante conceituação em registro configuracional - ou seja, mediante a caracterização de configurações -, pois a intermediação de interesses é realizada em determinadas posições institucionais estruturas -, cuja estabilidade e autoridade derivam, por sua vez, de sua inserção em arcabouços institucionais maiores. Em Schmitter, tais configurações são definidas como regimes. As estruturas de intermediação de interesses respondem às mesmas feições básicas já aludidas, mas dependendo da sua posição em relação ao arcabouço institucional do regime constitucional democrático e aos modos possíveis de expressão e representação de interesses - cidadãos, associações ou grupos, e classes ou sindicatos - configuram um regime específico de representação de interesses. Assim, nos termos de Schmitter (1992), as democracias seriam um compósito de regimes de representação, dentre os quais o regime eleitoral constitui apenas um, conectando cidadãos/eleitores, partidos e parlamento. As estruturas de intermediação corporativas do mundo do trabalho constituem o regime de concertação, que conecta atores dos interesses empresariais e trabalhistas com os órgãos centrais de decisão do governo. Ao mundo das organizaçóes civis e movimentos sociais, bem como dos grupos de interesses, corresponde aquilo que Schmitter chamou de modo indiferenciado de regime de pressão - 
uma espécie de categoria ou regime residual que englobaria o universo dos atores analiticamente privilegiados pelo pluralismo. ${ }^{5}$

Sem dúvida, atentar para a hierarquia ou altitude política na defesa de interesses dos atores sociais é traço distintivo da abordagem neocorporativa, e, nesse sentido, estruturas de concentração de poder adquirem saliência, pois é nelas que se ganha efetividade da representação de interesses. Assim, a perspectiva neocorporativa é particularmente propícia para iluminar configurações altamente cristalizadas e operantes em níveis de autoridade elevados. Não é fortuito que a literatura neocorporativa esteja sendo revisitada para interpretar o cenário das inovações participativas na América Latina (Chartock, 2013; Collier e Handlin, 2009; McNulty, 2013; Boschi, 2010), pois enseja afinidade analítica para a interpretação da institucionalização de instâncias que conferem protagonismo a setores sociais subalternos ou historicamente sub-representados nos circuitos tradicionais da representação.

Pois bem, os atores dos processos de institucionalização que nos ocupam neste momento histórico - OSCs e MSs - são consideravelmente mais heterogêneos que os atores protagônicos do neocorporativismo e a eles não é concedido monopólio algum da representação, embora sejam reconhecidos como atores com capacidades e, por vezes, funções de representação de determinados grupos sociais (Rezende, 2015; Gurza Lavalle e Isunza, 2011; Gurza Lavalle, Houtzager e Castello, 2006a, 2006b). Mais: a heterogeneidade guarda vínculo com uma diferença crucial, qual seja, a inexistência de interesses incontroversos a serem representados com prioridade sobre quaisquer outros interesses. Isto é, o mundo do trabalho não foi substituído por outro âmbito capaz de determinar sujeitos presuntivamente portadores de interesses univer-

5 No debate mais recente sobre a chamada crise da representação, as ideias de regimes de interesses de Schmitter passaram a ser exploradas pela literatura como diferentes circuitos da representação em registro pós-liberal (ver Schmitter, 2005; Arditi, 2005; Vite, 2005; Zaremberg, Gurza Lavalle e Guarneros-Mesa, 2017). 
sais ou superiores. Reconhece-se que interesses afetados precisam ser representados, mas tais interesses são diversos e não coincidem com um único porta-voz, antes, diversos atores concorrem com posições conflitantes. Logo, embora às OSCs e aos MSs seja atribuído status público na realização de certas funções, inclusive de representação, e existam canais institucionalizados de intermediação com o Estado como as chamadas instituições participativas mas não só -, trata-se de arranjos plurais. Ademais, tais arranjos, a despeito de sua institucionalização, são visivelmente vulneráveis e instáveis em comparação às instituições corporativas, e amiúde operam em regiões de intermediação ou altitude política de alcance médio, mediante um conjunto assaz diverso de canais de acesso ao funcionamento do Estado. Essa região mal corresponde ao chamado regime de pressão da abordagem neocorporativa, pois as distinções desenvolvidas com acuidade analítica para compreender o neocorporativismo do mundo do trabalho não encontram equivalente analítico com aderência empírica ao mundo heterogêneo da sociedade civil e aos arranjos institucionais que o vinculam com o Estado. 6

\section{Movimentos sociais e institucionalizações}

As abordagens pluralista e neocorporativa privilegiam analiticamente a inserção de interesses organizados em instâncias públicas incumbidas de tomar decisões, iluminando a institucionalização de interesses ora como resultado dessa influência sobre as decisões, na perspectiva pluralista, ora como monopólio da representação em instâncias de intermediação, no registro neocorporativo. Em ambos os casos, a capacidade de incidência desses interesses não é uma questão. No registro pluralista assume-se que

6 Para uma tentativa de incorporar explicitamente as OSCs e MSs no enquadramento neocorporativo ver Schmitter (1993). 
onde há interesses intensos eles se organizam ou associam e, uma vez organizados, as respectivas associações reagem quando os efeitos de decisões públicas colocam em jogo tais interesses; por outras palavras, associações são o desdobramento natural da intensidade de preferências nas sociedades organizadas politicamente em democracias (Dahl, 1991). Interesses desorganizados, não manifestos ou sem capacidade de incidência não são objeto de preocupação analítica. Por sua vez, no registro neocorporativo a capacidade de incidência dos sindicatos é um dado da história política do século $\mathrm{XX}$ e não precisa ser explicada. Apenas assume-se que quando determinados atores adquirem saliência suficiente para a reprodução da sociedade, eles tendem a ser reconhecidos e a tornar-se objeto da atribuição de status público, experimentando a dupla dinâmica da institucionalização descrita acima: aumento de influência sobre o Estado em troca de controle pelo Estado (Offe, 1998).

Para a literatura de MSs a institucionalização de movimentos e das suas demandas é questão relevante e, no entanto, teoricamente ambivalente quanto aos seus efeitos. De um lado, uma parte desse campo de investigação, ao privilegiar o confronto e posições dicotômicas entre movimento e Estado, identifica os processos de institucionalização com desmobilização e cooptação. De outro, avanços recentes ampliam e complexificam as formas de ação e organizacionais ao incluir aspectos de institucionalização, mas de forma pontual e sem dar conta dos processos e seus efeitos nos movimentos sociais e suas demandas. Nos parágrafos a seguir explicita-se o lugar analítico dos processos de institucionalização na literatura de movimentos sociais, mostrando de que maneira os conceitos de encaixes e domínios de agência aumentam a capacidade de analisar os movimentos quando estes adentram as instituições e institucionalizam suas demandas e sua posição em diversos setores de políticas públicas, notadamente, os das políticas sociais.

As principais e mais difundidas ênfases teórico-analíticas das teorias dos movimentos sociais elaboradas pelos autores 
radicados nos EUA não permitem descrever e explicar os processos de institucionalização que permeiam as interações dos movimentos sociais com o Estado para além da desmobilização e da cooptação. Isto, primeiro, porque pressupõem uma separação entre movimentos e a política institucionalizada, e analisam a sociedade e o Estado a partir de categorias estanques, como entidades autônomas e dicotômicas (outsider vs insider, challenger vs authority); e segundo, porque se baseiam em um modelo conflituoso de ação, construído dentro das relações de poder do sistema político que implica confronto entre atores não institucionalizados e institucionalizados (Tarrow, 1997; McAdam, Tarrow e Tilly, 2001; Tilly e Tarrow, 2007).

Um efeito dessas ênfases é a impossibilidade de se explorar a diversidade de interações entre os movimentos e o Estado, entre as quais estão as que se efetuam por meio das instituições e junto a atores institucionalizados. A exclusão do fenômeno supramencionado influiu na produção de uma noção estreita de institucionalização na literatura, focada nas ações de confronto político e nas organizações de movimentos. Se a institucionalização da ação equivale ao protesto rotinizado, no caso das organizações, a institucionalização implica uma complexificação organizacional do movimento, a qual é remetida à rotinização, previsibilidade, formalização, profissionalização e oligarquização da ação coletiva (Kriesi, 1999), e/ou à sua transformação em um ator institucionalizado como, por exemplo, em grupo de interesse ou partido político (Kriesi, 1999). Em ambos os casos, haveria como consequência a mudança nos objetivos que levaram a fundação do movimento no sentido da desradicalização, a eventual cooptação dos ativistas e, por fim, a desmobilização.

As ênfases no caráter confrontacional e conflituoso entre movimentos sociais e Estado e na separação analítica entre ambos foram contestadas por um conjunto de autores que introduziram 
aspectos da institucionalização sem associá-los, necessariamente, à cooptação de ativistas e à desmobilização de movimentos. As pesquisas conduzidas no Brasil (Abers e von Bülow, 2011; Abers, Serafim e Tatagiba, 2014; Carlos, 2012; Dowbor, 2012; Szwako, 2012; Silva e Oliveira, 2011; Tatagiba e Blikstad, 2011; Alonso, Costa e Maciel, 2007) e alhures (Banaszak, 2005; Goldstone, 2003; McAdam e Scott, 2005; Clemens, 1993, 2005; Giugni e Passy, 1998) demonstram que os movimentos sociais não podem ser reduzidos analiticamente às ações da política de confronto desencadeadas e sustentadas por organizações e redes informais. Esses estudiosos trazem novos elementos para descrever as interações via instituições entre movimentos e Estado, a partir de três assertivas. Primeira: os movimentos sociais se engajam em um conjunto de atividades que não necessariamente implicam a relação de conflito com os detentores de poder; em sociedades complexas, movimentos também cooperam com o Estado, colaborando na elaboração e implementação de políticas governamentais (Giugni e Passy, 1998; Carlos, 2012, 2015). Segunda: os movimentos sociais combinam uma pluralidade de formas de relação com o Estado, em modelos híbridos e criativos que promovem a articulação circunstancial entre ação institucionalizada e não institucionalizada (Abers, Serafim e Tatagiba, 2014; Carlos, 2012; Dowbor, 2012). Terceira: o uso de canais institucionalizados no repertório de ação e a formalização das organizações não leva obrigatoriamente à desmobilização do movimento (Carlos, 2012; Dowbor, 2012).

Mais concretamente, do ponto de vista analítico, o repertório de ação de movimentos sociais foi ampliado. Passaram a ser incluídas as interações cooperativas ou colaborativas entre movimentos e atores institucionais em torno da produção de políticas públicas (Giugni e Passy, 1998), bem como as interações por meio dos canais de acesso mais ou menos institucionalizado às agências do Estado, tais como lobby, instituições participativas e contato com os representantes políticos, entre outros (Abers, Serafim e 
Tatagiba, 2014, p. 346). As organizações de movimentos passaram a incluir variados tipos e a ser vistas como parte das estratégias de ação, mesmo quando acionadas sob formas altamente formalizadas (McAdam e Scott, 2005; Goldstone, 2003; Hanagan, 1998; Clemens, 1993).

Em outras palavras, os movimentos não necessariamente se movem num continuum de formas de ação menos institucionalizadas a mais institucionalizadas. Eles fazem uso diversificado e, por vezes, simultâneo dessas formas e ações a depender da análise das oportunidades e ameaças políticas. Com isso, torna-se possível romper com o diagnóstico da desmobilização e/ou cooptação como resultado necessário da simples existência de açôes via instituições. Tampouco existiria a transformação linear das formas organizacionais - de informais e espontâneas a altamente formalizadas, as primeiras correspondendo à mobilização do movimento e, as segundas, à desmobilização e transformação do movimento em um ator institucionalizado.

O afrouxamento das fronteiras analíticas entre o caráter confrontacional e cooperativo, e entre o caráter não institucionalizado e institucionalizado das ações e organizações de movimentos sociais nessas novas perspectivas é salutar e permitiu incorporar nas análises as instituições estatais e os atores do sistema político. Neste sentido, passou-se da análise de ações unilaterais do movimento para a análise de interações entre movimento e Estado. Contudo, tratadas de forma indiscriminada como açóes do repertório, as ações extrainstitucionais e via instituições têm todas o mesmo peso analítico, enquanto sabemos que podem ter efeitos distintos nas trajetórias de movimentos e no grau de sua influência nos processos decisórios. Ou seja, ao repertório de interação falta a abrangência analítica para iluminar os graus de institucionalização da ação e, com isso, identificar a capacidade de influência do movimento, bem como a própria institucionalização de partes do movimento. 
Por isso, precisamos de categorias que permitam observar os MSs em interação com as instituições do Estado e detectar as gradações de permanência e de influência dos atores sociais nos processos decisórios e seus efeitos. Categorias capazes de descrever os processos que consistem em buscar pontos de acesso ao Estado e em delimitar possíveis áreas de atuação reconhecidas pelo Estado, bem como fontes para a obtenção de recursos públicos sob o controle das organizações de movimentos. A abordagem da polity e seu conceito central, encaixe institucional, elaborados por Skocpol (1992), e revisados e expandidos por nós para o plano analítico de configurações de encaixes no interior da abordagem do domínio de agência oferecem essas lentes analíticas. As mudanças nos movimentos em termos de sua continuidade, desmobilização, cooptação ou transformação em outro formato de ação coletiva constituem, nesse sentido, possibilidades e não fatalidades que emergem necessariamente dos processos de institucionalização de médio alcance.

Porém, embora os receios da literatura quanto à institucionalização dos movimentos - de seus canais de diálogo com o Estado, seus repertórios e até de suas demandas - tenham imposto custos cognitivos, encerram uma questão de fundo que resta em pé após as críticas. Após a inclusão conceitual da institucionalização, o que garante que o fenômeno estudado ainda é, analiticamente, um movimento social? Há duas respostas para esta pergunta que estabelecem fronteiras analíticas próprias a esse tipo de ação coletiva. Em primeiro lugar, o ponto de partida dos estudos deve ser a operacionalização e a aplicação do conceito de movimentos sociais, que os distingue enquanto fenômeno de outros atores da sociedade civil. Esta reconstrução não é atemporal e genérica. Precisa ser feita num dado período histórico de modo que sejam evidenciados os elementos constitutivos do conceito como interações informais entre indivíduos, grupos e organizações, identidade coletiva e ações (Diani, 2003). Os conceitos de repertório de interação e 
de encaixes permitem acompanhar o desenvolvimento dessa ação coletiva, que adentra as instituições do Estado, e observar a institucionalização de canais de acesso, de demandas e de organizações, ainda no escopo do conceito de movimento.

Em segundo lugar, ao invés de deduzir a desmobilização e, uma vez pressuposta, simplesmente atestá-la mediante a pesquisa empírica, como o quer a teoria do confronto político, a observação dos processos de institucionalização permite avançar e mostrar a transformação da ação coletiva. Embora o conceito movimento social suponha, ao frisar a palavra informal, que se trata de uma forma instável de ação coletiva, reproduzir e permanecer nessa informalidade não precisa ser e amiúde não é um objetivo em si dos MSs. A razão é simples e traz consigo implicações profundas: a informalidade aumenta a contingência dos resultados da disputa política; por outras palavras, MSs estão em primeira instância comprometidos com a defesa de agendas substantivas e a institucionalização é um recurso para fazer avançar tais agendas e protegê-las das contingências da política. Perenizar os valores e interesses defendidos mediante a institucionalização é um resultado possível e inclusive almejável de processos de mobilização que não ocorre de modo unidirecional nem é definido de uma só vez, em um único momento ou circunstância. Assim, cabe ao analista observar os processos de institucionalização e, em última instância, identificar o ponto a partir do qual certas configurações de encaixes sedimentadas ao longo do tempo graças à ação coletiva trazem consigo a transformação do movimento social em questão em algum outro tipo de ator.

\section{Das variações horizontal, vertical e configuracional: encaixes e domínios de agência}

O neo-institucionalismo histórico oferece um registro alternativo graças, em primeira instância, a um pressuposto básico: o 
caráter mutuamente constitutivo das relações entre Estado e sociedade civil. O pressuposto é marca distintiva que subjaz os trabalhos dessa perspectiva, mas certamente é possível encontrá-lo em outros registros analíticos, por exemplo, nas reinterpretações de linhagem gramsciana da sociedade civil (Dagnino, 2011). De fato, ao longo das duas últimas décadas, o pressuposto tem sido explorado e tematizado continuamente pelos autores deste capítulo em registro crítico em relação à literatura de movimentos sociais e da sociedade civil (Gurza Lavalle, 1999; Houtzager, Gurza Lavalle e Acharya, 2004; Gurza Lavalle, Acharya e Houtzager, 2005; Gurza Lavalle, Houtzager e Castello, 2012; Carlos, 2012, 2015; Dowbor, 2012; Szwako, 2012, 2013; Gurza Lavalle e Szwako, 2015).

$\mathrm{Na}$ tradição neo-institucionalista o pressuposto da mútua constituição entre Estado e sociedade civil significou, já no começo dos anos 1990, um afastamento ante posturas State-centered e sua excessiva ênfase na autonomia das políticas - ênfase própria da primeira geração que trouxe, conforme mencionado na introdução, "the State back in". Centrar a análise na autonomia do Estado não foi operação analítica trivial, quando considerado que as compreensões predominantes propunham macro-interpretações de classe ou de fundo funcionalista modernizante para explicar as políticas de welfare (Skocpol, 1992). O Estado e sua atuação eram, assim, derivados de lógicas externas, a saber, da estrutura da sociedade. Contudo, a ênfase na autonomia do Estado cedeu passo a formulações analiticamente mais sofisticadas em que conceitos e explicações expressam interações socioestatais. Assim, Peter Evans (1995) reformulou seu diagnóstico acerca do sucesso de políticas de desenvolvimento em função da autonomia das instituições estatais incumbidas de definir tais políticas e avançou interpretação em que a inserção (embeddedness) do Estado em âmbitos societários era condição sine qua non de tal sucesso. Evans postulou, assim, benefícios funcionais para a capacidade de coordenação do Estado quando capaz de operar com autonomia socialmente inserida (embedded autonomy). 
$\mathrm{Na}$ condição de pressuposto, o caráter mutuamente constitutivo opera implicitamente guiando o olhar do neo-institucionalismo, mas não foi objeto de teorização. Para nós, a lógica de mútua constituição implica não apenas considerar incorretas e cognitivamente custosas compreensões dualistas e dicotômicas entre Estado e sociedade civil, mas ir além de compreensões contextualistas - comuns inclusive no neo-institucionalismo histórico - e entender a relação entre ambos de modo endogênico, interacionista e codeterminante. Que as instituições do Estado não pairam no ar desencarnadas das disputas políticas e dos interesses sociais, e que a sociedade civil e os MSs são simultaneamente estabilizados pelos direitos fundamentais consagrados constitucionalmente e constrangidos pelos marcos legais das sociedades em que atuam, são diagnósticos em maior ou menor medida pacíficos nas ciências sociais - embora não o sejam suas implicações. Contudo, pensar o Estado como contexto da sociedade e vice-versa é insuficiente. Interesses sociais organizados não apenas pressionam externamente o Estado - ao estilo pluralista -, mas são encarnados e ganham expressão institucional no Estado. Como argumentado há mais de um século e meio por Marx e pelo marxismo (e antes por Hegel), Estado e sociedade guardam vínculos constitutivos internos. Contudo, nem a sociedade civil pode ser absorvida no Estado, como queria Hegel, nem o Estado pode ser reduzido à sociedade civil, como queria Marx. As capacidades de ação de atores sociais e instituições políticas são politicamente produzidas (gênese) pelas disputas entre atores estatais e sociais. A construção política dessas capacidades decorre de processos de interação entre os atores, processos condicionados pelos resultados das interações prévias. No

\footnotetext{
Como será visto ainda nesta seção, o caráter contextual dessas relações tornase pertinente quando comparam-se escalas distintas na mesma análise; por exemplo, ações de escala micro condicionadas por regulações macro. Contudo, as regulações macro também foram politicamente produzidas por atores agindo nessa escala.
} 
processo histórico dessas interações ocorre a codeterminação ou mútua constituição entre Estado e sociedade civil.

Especificamente para questão que aqui interessa, e a despeito de sua subteorização no neo-institucionalismo histórico, o pressuposto da mútua constituição levou à construção de conceitos que permitem iluminar a relação entre institucionalização e movimentos sociais. Aqui a contribuição seminal foi de Skocpol (1992, pp. 47-54), formulada sob o título de abordagem da polis (polity approach) em seu Protecting Soliders and Mothers e ancorada no conceito encaixe institucional (institutional fit). A abordagem ensejou desdobramentos analíticos e de pesquisa em duas direções complementares - contextual e relacional -, mas com implicações teóricas distintas para a compreensão da ação coletiva. De um lado, em registro contextualista, a proposta da autora estimulou estudos atentos à influência institucional do Estado e do sistema político sobre a disposição de agir e as capacidades de ação dos atores sociais; de outro, em registro relacional e atento à gênese, animou indagações debruçadas sobre a construção histórica dessas capacidades em termos da moldagem de encaixes institucionais ou entradas preferenciais (points of access) arquitetados pelos atores sociais no Estado (engineering fit). No primeiro caso, a adequação ou encaixe $(f i t)$ das formas e recursos organizacionais dos atores ao contexto macro e meso institucional favoreceria sua capacidade e disposição de agir. Corresponderia àquilo que Skocpol (2008) denominou de "efeitos indiretos" do Estado sobre a ação dos atores sociais. No segundo caso, as instituições não são contexto externo, mas produzidas no processo de construção das capacidades de ação dos atores ou, de modo mais preciso, embora abstrato, são endógenas ao processo estudado e não exógenas ou meramente contextuais. O primeiro registro é de índole tipicamente institucionalista e constitui expressão específica da tese geral "instituições importam" (institutions matter); já o segundo acusa a raiz sociológica do neo-institucionalismo histórico e é eminentemente relacional. 
É esse registro relacional próprio da sociologia política que interessa radicalizar aqui. Em todo caso, Skocpol articula ambas as possibilidades em seus trabalhos mantendo o mesmo conceito (Skocpol, 1992; Skocpol e Crowley, 2001; Skocpol, 2003).

Nos últimos anos, as duas direções registraram avanços significativos com implicações críticas para as teorias dos movimentos sociais, em particular para os autores inscritos na vertente do processo político. Em alusão a eles, Edwin Amenta et al. (2002) argumentaram que o Estado permanece infrateorizado pela contentious politics e que noções como "oportunidade política" tendem a repor a dicotomia entre atores estatais e não estatais. Como corolário, a crítica levou seus autores a forjar o modelo da "mediação política” (Amenta et al., 2005) e a questionar quais variáveis propriamente institucionais explicam os efeitos dos movimentos sobre a institucionalidade (Amenta et al., 2010). Em Amenta, a "caixa preta" Estado é examinada em suas dimensões internas - estrutura de autoridade, elites, eleições, políticas, burocracias e partidos -, mas as instituições permanecem em boa medida em registro contextual. Por outro caminho, Elisabeth Clemens se dedicou aos encaixes institucionais, partindo, porém, de uma dimensão negligenciada nos estudos do processo político: a sua lógica organizacional. Essa autora se volta para as inovações no "repertório organizacional" das mulheres estudadas por Skocpol, bem como para os efeitos dessas inovações na interação com o arcabouço institucional político estadunidense (Clemens, 1993). Em Clemens (1993), o repertório organizacional apenas faz sentido se entendido relacionalmente. Amenta e Clemens constituem esforços notáveis de desenvolvimento do neo-institucionalismo histórico para sanar seu subdesenvolvimento teórico no estudo dos MSs e ambos proveem distinções analíticas que fazem render os princípios ou pressupostos básicos dessa vertente do neo-institucionalismo e, mais especificamente, da obra de Skocpol nas duas direções apontadas. 
A compreensão dos processos de institucionalização dos MSs permanece, todavia, subexplorada e subteorizada. Em Skocpol os encaixes institucionais carecem de especificação sistemática e são simplesmente definidos como a adequação entre os objetivos e capacidades dos atores sociais e os pontos mutáveis de acesso ao Estado, sendo que essa adequação aumenta o acesso e alavanca a capacidade de ação desses atores (Skocpol, 1992, pp. 41, 54 e ss.). Encaixes, todavia, variam quanto às suas feições básicas e quanto ao nível de autoridade em que operam, e tais qualidades também variam quanto aos seus efeitos sobre a propensão dos atores sociais a agir e a fazê-lo com êxito. A baixa especificação analítica do conceito encaixes levou a autores como Houtzager e Kurtz (2000; Houtzager, 2004) a qualificar um tipo de encaixe mais potente - "vínculos estruturais" -, propício para a articulação de atores coletivos.

Aqui, evitamos a acepção contextualista dos encaixes institucionais e optamos por entendê-los em registro afim à tese da mútua constituição. Encaixes, em formulação mais restritiva e relacionalmente mais radical, são aqui definidos como sedimentações institucionais de processos de interação socioestatal que ganham vida própria (artefatos: instrumentos, regras, leis, programas, instâncias, órgãos) e mediante as quais atores sociais são, em alguma medida, bem-sucedidos em dirigir de modo contínuo a seletividade das instituições políticas ao seu favor, ampliando sua capacidade de agir. Fit admite em inglês o sentido de substantivo (encaixe) e de verbo (encaixar), pelo que essa dupla conotação evita eliminar a agência dos atores e conceder demasiada fixidez ao encaixe como instituição, pois o encaixe seria simultaneamente "o encaixar", ${ }^{8}$ um processo em construção contínua que supõe ação e atores. Ao definir o encaixe como uma sedimentação institucional

8 Agradecemos expressamente a Rebecca Abers por nos chamar a atenção para esse ponto. 
atentamos para esta dupla conotação, ele é simultaneamente o resultado de processos de interação e uma criatura ou artefato institucional que adquire densidade própria.

Privilegiar uma concepção não contextualista dos encaixes não equivale a propor que tudo o que importa no fenômeno da institucionalização é endógeno aos correspondentes processos de interação socioestatal - nem é isso que aqui postulamos. Constrangimentos e oportunidades exógenos ou contextuais existem, mas os ganhos analíticos de defini-los como encaixes são menos potentes, atentando para o fato de o contexto institucional maior importar na definição das estratégias dos MSs e das OSCs, bem como nos seus resultados. Alternativamente, a definição de encaixe como sedimentação institucional de processo de interação socioestatal outorga centralidade a constrangimentos e oportunidades endógenos a esse processo, bem como aos atores nele engajados, apontando os rumos a serem seguidos pela indagação empírica.

A rigor, e partindo do pressuposto da mútua constituição, a diferença entre constrangimentos e oportunidades exógenos e endógenos não é, para nós, de natureza ontológica, mas metodológica quanto ao foco de observação e fenomenológica quanto à percepção dos atores. Assim, regras definidas no nível federal operam como contexto das possibilidades de ação dos atores no nível municipal, mas elas próprias são produto de processos de interação socioestatal que envolvem outros atores agindo nessa escala. $\mathrm{Na}$ medida em que o processo de interações socioestatais focado se restrinja ao plano local e/ou a uma determinada política, outros processos e seus resultados em outros níveis federativos e/ou em outros setores de políticas são passíveis de definição como "contexto" em decorrência de uma opção metodológica e não pelas suas qualidades ontologicamente distintas. Por sua vez, os resultados desses outros processos são percebidos e vividos pelos atores como limites à sua atuação. Ainda assim, conforme será visto, parece 
mais pertinente "flagrar" o "contexto" em operação nos processos socioestatais como mecanismo interveniente do que como um fator constante pairando sobre a ação dos atores.

Isso posto, e conforme explicitado na seção inicial, encaixes variam horizontal e verticalmente, ou seja, quanto a suas especificidades e à hierarquia de autoridade em que operam. Canais de transmissão de informação, instâncias de fiscalização, cogestão de serviços, criação de programas ou políticas públicas, e inclusive a ocupação de cargos, podem ser, em processos de interação socioestatais, tanto encaixes arquitetados pelos atores sociais quanto capacidades adquiridas de atuação pelo Estado, mas possuem características e implicações políticas consideravelmente diferentes. A variação horizontal e vertical dos encaixes demanda, assim, maior especificação analítica. Mais: a articulação de diversos encaixes pode trazer consigo configurações emergentes de interação socioestatal que operam conectando diversos encaixes, com alguma estabilidade, em altitudes ou níveis de hierarquia diferentes, ou seja, com maior ou menor alcance político. Levar em consideração a articulação vertical e horizontal dos encaixes é relevante precisamente porque permite diferenciar quando operam configurações de encaixes de maior alcance e potência (domínios de agência) e quando se trata simplesmente encaixes avulsos ou em alguma medida desarticulados entre si.

Como sedimentações institucionais e produtos de processos de interações socioestatais, encaixes favorecem a agência dos atores sociais diretamente engajados nesse processo e daqueles que com eles guardam semelhanças funcionais e organizacionais. Assim, a forma organizacional sindicato é privilegiada pela legislação trabalhista, e não apenas os atores específicos que na história do sindicalismo conquistaram reconhecimento estatal. Encaixes, nesse sentido, são sedimentações institucionais de índole pública e, uma vez produzidas, não garantem controle exclusivo aos atores que as produziram. Assim, encaixes conferem alguma agência com 
certa duração a determinados tipos de atores, e não apenas àqueles diretamente envolvidos no processo de institucionalização. Leis, regulações, cargos e cadeiras ou vagas, órgãos e organismos, técnicas e instrumentos de políticas podem ser encaixes quando emergem como sedimentações institucionais de interações socioestatais e "fazem" os atores agir. Nem toda disposição legal, cargo, órgão ou instrumento de políticas constitui um encaixe. Por sua vez, nem toda conquista das OSCs ou dos MSs constitui encaixes, pois os últimos alongam no tempo a capacidade de influência dos atores concedendo-lhes alguma vantagem e algum grau de agência.

Arquitetar encaixes institucionais é conveniente para os movimentos sociais porque resguarda interesses e capacidade de (re)ação ao reduzir a contingência. Embora pareça contraintuitivo, encaixes operando em níveis de menor alcance político não são necessariamente menos institucionalizados do que configurações de encaixes inscritas em planos mais elevados. Por exemplo, uma peculiaridade dos instrumentos de políticas é que são modos de resolver certos problemas, aplicados de modo recorrente e sancionados como modos de proceder corretos (Lascoumes e Le Galès, 2007). Assim, um instrumento de políticas como um cadastro pode sobreviver como recurso "técnico" à despeito das mudanças de governo e de dinâmicas políticas gerais. Contudo, encaixes de altitude política elevada são especialmente valiosos para os atores coletivos, pois quanto maior o nível de autoridade em que ocorre a institucionalização, menor a contingência dos interesses resguardados pela mesma. Igualmente, a disposição de um número maior de encaixes articulados entre si é mais valiosa, do ponto de vista dos atores, do que a existência de um número menor de encaixes avulsos. A combinação entre um número maior de encaixes institucionais articulados entre si e sua inscrição em níveis de autoridade mais elevados é conveniente para os movimentos sociais, precisamente, porque resguarda seus interesses da contingência e poupa os atores de ter que disputar novamente amanhã as batalhas 
vencidas hoje. Afinal, instituições são decisões políticas congeladas no tempo (March e Olsen, 1984). Certamente, institucionalização não elimina o conflito nem salvaguarda definitivamente os interesses dos movimentos engajados em processos de interação socioestatal, mas desloca a disputa para um terreno relativamente mais favorável.

A articulação vertical e horizontal de conjuntos de encaixes perfila configurações variáveis e define uma propriedade básica dos dominios de agência. Domínios constituem esferas de competência e, neste caso, a competência diz respeito à capacidade de agir em determinado âmbito sob responsabilidade direta ou indireta do Estado, notadamente em campos de políticas sociais (Gurza Lavalle, Houtzager e Castello, 2012). Assistência social é, por exemplo, domínio de agência não apenas tradicional, mas centenário se considerada sua evolução a partir de benemerência e da filantropia (Gutirerres, 2015). Aos atores desse domínio reconheceu-se tradicionalmente a legitimidade para agir na intermediação de recursos públicos no atendimento de segmentos da população demarcados por determinadas vulnerabilidades. Instrumentos foram criados para viabilizar essa atuação, canais de comunicação foram definidos e mecanismos de certificação do trabalho desses atores foram criados. Sem dúvida, no Brasil pós-transição a multiplicação de domínios de agência mais notória corresponde à área de saúde, nos campos da atenção básica, da saúde da população negra, da política de HIV/Aids, do ensino e pesquisa da medicina social, para mencionar apenas alguns exemplos da área. Contudo, o pós-transição trouxe no seu bojo diversos processos de interação em que outros MSs como o feminista, ambientalista, de moradia, dos novos migrantes, negro, LGBT ou indígena avançaram no sentido da institucionalização, em alguns casos configurando domínios de agência.

Domínios de agência são configurações de encaixes institucionais articulados vertical e horizontalmente que favorecem a 
capacidade de agir de certos atores coletivos. Favorecem-nos porque: (i) implicam o reconhecimento de que os atores tem legitimidade para agir e demandar em nome de grupos específicos ou interesses difusos (embora não concedam monopólios na representação); (ii) selecionam e processam com maior frequência problemas e demandas relevantes para esses atores (ainda que com eles não definam uma relação de exclusividade); (iii) outorgam suporte material - organizacional ou financeiro - aos atores propiciando sua estabilização (ainda que não garantam financiamento permanente); e (iv) reduzem o poder de concorrência de atores estranhos ao domínio de agência (mesmo que não entreguem aos atores favorecidos o controle sobre as barreiras de entrada). Trata-se de domínios de agência porque institucionalizam âmbitos de atuação que animam a capacidade de ação dos atores, "fazem-nos" agir estimulado sua condição de agentes. Por outras palavras, são domínios de agência porque neles se reconhece e favorece a capacidade de agir e decidir de determinados atores - ênfase que em inglês poderia ser mais intuitivamente percebida sob a formulação domains of agency, diferente de agency domains. A ideia de "domínios", por sinal, é comum na literatura especializada em políticas públicas, não raro focando as disputas e alianças dos atores em diferentes domínios de políticas (ver, por exemplo, Browne, 1990; Chambré e Fatt, 2002; Salisbury, Heinz, Laumann e Nelson, 1987; Knoke, 1993). A ênfase aqui é nos atores e na capacidade que eles têm de agir em relação aos processos de institucionalização; essa agência não necessariamente coincide com (ou se ordenam sob) a lógica setorial das políticas.

A abordagem de domínios de agência não é, prima facie, uma proposta normativa, na medida em que não assume que a institucionalização é "boa" a priori conforme algum parâmetro externo de avaliação, nem que os atores politicamente alavancados pela sua inscrição em determinado domínio atuem em prol do "bem comum" ou genuinamente em nome dos grupos sociais que 
invocam na sua mobilização, ou sequer que os encaixes serão apenas utilizados pelos MSs engajados diretamente na sua produção. Obviamente, MSs de orientações políticas as mais diversas podem se engajar em processos históricos de institucionalização de seus interesses e agendas no Estado. Pressupomos apenas que do ponto de vista dos MSs há benefícios associados à institucionalização e assumimos ser desejável que MSs tenham condições de vocalizar os conflitos sociais, de politizar questões de baixa notabilidade na agenda pública e de escolher as estratégias de ação que julgarem mais pertinentes para pressionar o Estado dentro do marco geral do respeito aos direitos humanos.

\section{Breve consideração metodológica: processos, causas, efeitos e mecanismos}

Em termos metodológicos, a abordagem de domínios de agência torna endógenos aos processos de interação socioestatal fatores que comumente figuram, nas explicações causais, ora como contexto externo ora como variáveis independentes - oportunidades e restrições políticas, capacidades estatais, repertórios de ação e identidades, alianças pluriclassistas, recursos organizacionais, entre outras. De índole processual, a abordagem de domínio de agência substitui o enfoque contextual e exógeno pelo enfoque dinâmico e relacional dos processos políticos, cujas condições são apreendidas como mecanismo simultaneamente produtor e produto das interações socioestatais. Conquanto os mecanismos por definição tenham efeitos recorrentes nos processos políticos, suas consequências ao longo do tempo variam consideravelmente dependendo das condições iniciais e das combinações com outros mecanismos (Tilly, 2001). Ademais, as condições que incidem sobre processos políticos devem ser examinadas em associação entre si, pois os mecanismos intervenientes na interação socioestatal ao mesmo tempo em que contribuem na construção de encaixes e 
configurações de encaixes são por eles produzidos - inócuo estabelecer causas primas.

Encaixes institucionais e a eventual construção de domínios de agência são produtos do processo de interação socioestatal que potencializam a agência de atores sociais, cuja reconstrução e resultados demandam uma agenda de pesquisa. Em outras palavras, pela abordagem do domínio de agência é esperado que a institucionalização seja propicia a agência de MSs e OSCs, pois institucionalização diz respeito à disposição de condições comparativamente mais favoráveis que lhes propiciam agir em face do Estado e de outros atores sociais e privados; entretanto, diagnosticar sua ocorrência e implicações é tarefa da pesquisa empírica.

Assim, não são postuladas relações causais gerais no que diz respeito aos resultados de se arquitetar encaixes e se construir domínios de agência, mas mecanismos, enquanto regularidades associadas aos processos de causação, guardam aqui afinidade com uma abordagem processual - como a do domínio de agência. Encaixes arquitetados pelos atores no Estado e domínios de agência que conferem legitimidade de agir e poder de influência na política e no processo de decisão são construções históricas contingentes e não fatalidades. Mecanismos intervêm, de modo isolado ou em combinação com outros mecanismos, nos processos de interação e alteram os modos e as chances da institucionalização - ao mesmo tempo em que são por eles afetados. É tarefa do escrutínio empírico em profundidade dos processos de construção de encaixes por atores sociais, desde sua gênese até sua eventual consolidação institucional em domínios de agência, identificar mecanismos específicos operando quer nas especificidades ou feições dos encaixes (variação horizontal) quer em sua hierarquia política ou autoridade (variação vertical) ou na sua articulação sob determinadas configurações (domínios de agência).

Grosso modo, e apenas à guisa de consideração metodológica, é possível sugerir a busca de três tipos de mecanismos, a saber, 
mecanismos institucionais, mecanismos relacionais e mecanismos sociais. Os mecanismos institucionais consistem em condições que afetam as instituições políticas visadas na formação de encaixes, a exemplo da permeabilidade do Estado, da composição partidária e eleitoral dos poderes legislativos e executivo, e das capacidades estatais. A permeabilidade do Estado, enquanto conjunto de instituições e atores heterogêneos, opera sobre a incidência das OSCs e MSs nas políticas públicas. O grau de porosidade do Estado às demandas dos atores coletivos, e a associação dos últimos a alianças partidárias e eleitorais, favorecem a construção de encaixes na burocracia estatal. As capacidades estatais no provimento de normativas legais, recursos administrativos, humanos e financeiros voltados a operar a política são igualmente mecanismos intervenientes na construção de encaixes institucionais, pois exprimem a acessibilidade ao e a competência do Estado para operar setores e aspectos específicos da política pública. Ainda que encaixes instituídos possam se articular a outros encaixes e consolidar em domínios de agência, as capacidades do Estado na política afetam a amplitude da influência dos atores sociais no processo decisório.

Os mecanismos relacionais correspondem a estrutura de vínculos das OSCs e MSs com sua rede de relações informais e sua rede de apoiadores e coalizões, ao longo do tempo. Isso inclui as redes de ativismo do movimento e de articulação dos atores sociais e organizacionais na defesa de demandas compartilhadas em relação a determinado setor de política, bem como as alianças ou coalizões com instituições do executivo, legislativo e do sistema de justiça, partidárias, religiosas e organismos internacionais - constituídas ao longo do tempo frente a oportunidades de influir no processo político. Em processos de interação socioestatal, a formação de redes de movimento e de redes de apoiadores, o papel de intermediação, coordenação e articulação de brokers, potencializam a influência dos atores coletivos na política pública, condicionando a construção de domínios de agência. 
Por fim, os mecanismos sociais correspondem às capacidades de ação dos atores das OSCs e MSs para arquitetar encaixes institucionais e construir domínios de agência. Em geral, são expressas nas formas organizacionais e nos repertórios de ação coletiva acionados nos processos de interação com o Estado, incluso formatos mais formalizados, especializados e profissionalizados de organizações de movimentos e de associações civis. As capacidades de agir revelam o aprendizado dos atores sociais, sua expertise e saber para operar políticas específicas, atuar como incubadores de instrumentos de políticas e interagir com o modus operandi da administração pública, sendo igualmente forjadas em processos pretéritos de interação socioestatal e de institucionalização.

Nos processos históricos de institucionalização - conduzam ou não a domínios de agência -, os mecanismos são interdependentes e complementares na construção de encaixes com vistas à incidência nas políticas. Entretanto, e conforme dito, conquanto cruciais, os mecanismos não devem ser concebidos como determinantes causais e sua ausência como impeditiva apriorística da construção de encaixes. Isso pois, as condições que favorecem a amplitude de influência dos atores nas decisões políticas e sua conversão em domínios de agência podem ser forjadas no processo mesmo de interação com o Estado e as instituições. Consonante ao pressuposto de mútua constituição entre Estado e sociedade civil, mecanismos, sejam eles institucionais, relacionais, sociais ou de outra possível índole, tanto condicionam processos de institucionalização, enquanto herança de interações socioestatais pretéritas, quanto são ensejados por esses últimos quando a institucionalização em foco gera encaixes que, como artefatos, aparecem como condição da ação ulterior de outros atores coletivos. Assim, a construção de encaixes e sua ativação ao longo do tempo guarda relação com o desenvolvimento de capacidades organizacionais dos atores sociais, por exemplo, mediante a complexificação organizacional das OSCs e MSs (via a gestão de programas e projetos governa- 
mentais, e a ocupação de cargos por ativistas, por exemplo) ou mediante a produção de condições propícias para a formação de redes de recrutamento e/ou de apoiadores, de articulações e coalizões de defesa de causas, ou, até mesmo, para a emergência de novas organizações dedicadas a articulação de redes (encontros, fóruns, comissões, conferências, conselhos e grupos de trabalho). Encaixes institucionais e domínios de agência, conforme será mostrado a seguir, também guardam relação com construção de capacidades estatais, criando ou ampliando-as, por exemplo, mediante inovação ou experimentação socioestatal em instrumentos de políticas, criação de órgãos, adoção de categorias cognitivas ou desenvolvimento de habilidades específicas em segmentos das burocracias.

\section{Do outro "lado": as capacidades do Estado}

O diálogo até aqui empreendido com perspectivas realistas, diálogo de tom crítico com o pluralismo e revisionista com o neocorporativismo, inspirou os delineamentos da noção de domínio de agência. Já as implicações analíticas (subteorizadas, como vimos) da agenda do neo-institucionalismo histórico nos legaram, pari passu a noção de encaixes institucionais, uma apreensão radicalmente relacional das dinâmicas pelas quais valores, interesses e reclamos das OSCs e dos MSs tendem a e podem ser cristalizados em instituições. Vamos, por fim, dispor em linha de continuidade argumentativa com as noções de domínio de agência e encaixes institucionais a noção de capacidade estatal, posicionada como componente analítico-descritivo incontornável na compreensão das chances de acesso e sucesso institucional quanto à vocalização dos atores não estatais. Trata-se, aqui, de uma implicação cognitiva: a uma lógica explicativa focada nas interações socioestatais corresponde um descentramento que leve em consideração o "outro lado" das equações socioestatais, com fins a determinar qual o papel do componente estatal naquelas interações. Para explicar 
tal descentramento dedicado às capacidades estatais voltemo-nos, primeiramente, a uma definição de capacidade estatal (definição provisória e não institucionalista, porém útil mais adiante) para passar, em seguida, à trajetória ocupada pela State capacity no neo-institucionalismo histórico, de suas raízes às posteriores gerações, nuances e inflexões.

Em sua definição mais enxuta, capacidade estatal pode ser entendida como "a competência (ability) dos Estados de formular e implementar políticas" (Kjaer et al., 2002, p. 20). Já na grade da contentious politics, capacidade estatal designa "o grau de controle que os agentes estatais exercem sobre pessoas, atividades e recursos no âmbito da jurisdição territorial do seu governo. Quando aumenta a capacidade estatal", dizem McAdam et al. (2004, p. 78), "isso se dá através de quatro processos, em geral, complementares: a substituição de um governo indireto por um direto; a penetração por Estados centrais em periferias geográficas; a padronização de práticas e identidade estatais, e a instrumentação - [isto é, o] crescimento dos meios de execução das políticas pretendidas" (destaques no original). Notem-se aí diferenças de registro entre o que o Estado faz e como o faz. A primeira definição aglutina ambos os registros: como faz (sua competência) e o que faz (formula políticas e as implementa). Na definição de McAdam, Tarrow e Tilly ganha-se em especificação: o "como" da ação estatal entra em cena, em especial, com a noção de "instrumentação", sendo que em nível conceitual mais amplo importa "o que" o Estado faz, isto é, seus "graus de controle". Foi esta última acepção de capacidade estatal que, primeiramente, ocupou o centro heurístico das obras, não do neo-institucionalismo histórico, mas daquela corrente que ao lado de J.P. Nettl foi uma de suas matrizes intelectuais, qual seja: a produção da sociologia histórica de meados dos 1970 - não por acaso, disparada por Tilly e Skocpol.

A crítica a explicações de cunho societal ou de tom modernizante sobre o então chamado "desenvolvimento político" levou 
C. Tilly e outros (1975) a perscrutar os processos sociopolíticos na gênese dos Estados modernos. "[Nosso] viés [de análise]", diz Tilly (1975a, p. 6), "foi deliberado. A especificação da organização das forças armadas, da taxação, do policiamento, do controle do fornecimento de alimentos e da formação de pessoal técnico põe em relevo atividades que foram difíceis, custosas e, não raro, indesejadas por grande parte da população". Tais "atividades" são competências estatais historicamente disputadas e construídas vis-à-vis populações locais, em geral, malgrado estas últimas. A gênese e a sobrevivência, ou não, dessas atividades de controle e extração - de recursos humanos, materiais e naturais - variaram histórica e culturalmente, mas os elementos que compuseram a equação fundamental dos processos de State-building foram três. "Primeiro, há a população que leva alguma vida política coletiva [...]. Em segundo, há uma organização governamental que exerce controle sobre os principais meios de coerção da população. Em terceiro, há relaçôes rotinizadas entre a organização governamental e a população" (Tilly, 1975a, p. 32). No meio dessa equação, e como resultado da interação entre esses elementos, foram negociados e produzidos direitos que transformaram súditos em cidadãos. Em versão mais recente, Tilly (1996 [1990]) aprofundou o argumento segundo o qual os tipos de direitos tanto produzem como seguem a ampliação da capacidade de atuação estatal frente às demandas e barganhas com parcelas expressivas das populações. Aquelas "relações rotinizadas" passaram a ocupar, nesse argumento, o centro do que hoje chamamos de "cidadania", "[que] consiste de múltiplas negociações elaboradas pelos governantes e estabelecidas no curso de suas lutas pelos meios de ação do Estado, principalmente pela guerra" (Tilly, 1996, p. 164).

Se a guerra ocupou lugar central nos macrodiagnósticos de construção de Estados, ela esteve desde sempre vinculada e remetida a outras capacidades estatais naquele naipe de explicações. Exemplo disso pode ser visto na clássica análise de T. Skocpol que, 
antes mesmo de reivindicar "o Estado de volta à cena”, insistia que "a vontade e a capacidade dos Estados para levar adiante mudanças econômicas nacionais são influenciadas pela sua situação militar e pelas pré-existentes capacidades políticas e administrativas militarmente relevantes" (1979, p. 22; destaque nosso). De forma original nas análises de grandes revoluções, Skocpol enfatizou o componente das organizações de Estado, lançando luz sobre os conflitos (fossem eles internacionais, internos à sociedade política ou domésticos com a população) e somando-as ao rol de explicações que tendiam a resumir tais revoluções a dinâmicas societais. Assim, enquanto para outras chaves as causas básicas de "crise do Antigo Regime” seriam relativas à perda de legitimidade, surto modernizador ou renovação de dominação de classe, explicações como as de Skocpol e as de Tilly (2003), centradas no Estado, enfatizam graus de controle estatal, bem como as crises neles ocorridas quanto a dinâmicas de reprodução institucional - crises na taxação ou no emprego da força repressiva, por exemplo. "Em outras palavras, as práticas e estruturas estatais importam para a formação mesma de movimentos revolucionários bem como para seu destino subsequente" (Goodwin, 2003, p. 410).

Constante embora discreta, a noção de capacidade estatal atravessou gerações e agendas de pesquisa. Na primeira metade dos anos 1980, a afirmação de que "o Estado importa" insistia no fato de que o Estado não deveria ser entendido como mero contexto para disputas quer entre classes ou grupos. Interessantemente, tanto na reconstrução hercúlea de M. Mann como no programa de Bringing the State Back In, o sentido da crítica a explicações políticas por variáveis extrainstitucionais assumiu tom weberiano. Estados são definidos "como organizações que reivindicam o controle sobre territórios e pessoas e que podem formular e perseguir objetivos que não são simplesmente reflexos das demandas ou interesses de grupos sociais, de classes ou da sociedade. Isto é o que geralmente se entende por 'autonomia do Estado'” (Skocpol, 1985, p. 9). 
Igualmente, tanto no registro de Mann como no de Skocpol, Evans e Rueschemeyer se dá uma espécie impensada de sinonimização entre autonomia do Estado e capacidades estatais. "A explicação das capacidades estatais", diz Skocpol, "está fortemente ligada à explicação da formação de objetivos autônomos pelo Estado" (1985, p. 16). ${ }^{9}$ Noutro registro, porém de lógica análoga, as principais formas de poder estatal, tal como pensadas por Mann, são capacidades, ${ }^{10}$ mais que sinonimizadas, dissolvidas na noção de autonomia "A autonomia do Estado, tanto da forma despótica como da infraestrutural, decorre principalmente da competência única do Estado de fornecer uma forma de organização territorialmente centralizada" (Mann, 1984, p. 185; destaque no original).

Respondendo a uma lógica de debate intelectual com e contra interpretações marxistas e pluralistas, a veia enfática do neo-institucionalismo sobre a autonomia do Estado rendeu efeitos frutíferos (Skocpol, 1995). Trouxe explicitamente consigo a noção de capacidade estatal para o núcleo heurístico de sua agenda - "as capacidades do Estado de implementar estratégias e políticas merecem análise detalhada por direito próprio" (Skocpol, 1985, p. 16) - levando-a a outros diapasóes, sendo afiançada mesmo pelo institucionalismo à la escolha racional..$^{11}$ Além disso,

9 À conclusão, P. Evans, D. Rueschemeyer e T. Skocpol diziam que "junto das táticas analíticas para investigar as capacidades do Estado, os ensaios aqui coletados também oferecem idéias sugestivas e novas questões sobre a dinâmica da autonomia estatal" (destaque no original) (1985, p. 353).

${ }^{10}$ Cf. "Podemos denominar esse poder infraestrutural, [como] a capacidade do Estado de penetrar na sociedade civil e implementar decisões políticas logisticamente ao longo do território" (Mann, 1984, p. 189; destaque no original). Devido a essa espécie de dissolução da capacidade estatal na noção de autonomia, não há, neste primeiro M. Mann (1984), um raciocínio iterativo, mas sim extrativo, no qual o Estado extrai recursos da sociedade civil para fortalecer capacidades suas. Como veremos adiante, no entanto, a lógica subjacente à noção de poder infraestrutural muda relacionalmente em Mann tornando-se um raciocício de "mão dupla" (Mann, 1993, p. 59).

11 Também no registro da rational choice parece ter operado a sinonímia capacidadesautonomia. "A capacidade de implementar políticas iniciadas pelo Estado [state-initiated policies, no original]", diz B. Geddes, "depende da competência 
essa postura State-centered não levou necessariamente a uma reificação do Estado; correspondeu, antes, a uma lógica iterativa de análise na qual as relações Estado/atores não estatais pesam sobre as preferências destes últimos; "os significados da vida pública e as formas coletivas por meio das quais os grupos tomam consciência dos objetivos políticos e o trabalho para alcançá-los surgem, não apenas das sociedades, mas nos pontos de encontro de Estados e sociedades" (1985, p. 27).

Autocriticada, essa agenda operou relevantes deslocamentos analíticos que, além de terem dado enraizamento sociopolítico à noção de autonomia (Cf. Evans, 1995), estão bem sintetizados na passagem de um paradigma "State-centered" para outro "polity-centered". ${ }^{12}$ Se essa inflexão operada por Skocpol (1992) legou uma noção como a de encaixes, deu também continuidade àquela posição, discreta, ${ }^{13}$ ocupada pela noção de capacidade estatal no neo-institucionalismo histórico. Caso exemplar dessa continuidade pode ser visto na análise de The People's Lobby (Clemens, 1997), a respeito da mobilização de associações voluntárias nos Estados Unidos de fins do XIX e início do XX. Aí E. Clemens se dedica às interações travadas por organizações de fazendeiros, de trabalhadores e de mulheres com subpartes do governo estadunidense sublinhando efeitos político-institucionais nada

para tributar, coagir e moldar os incentivos que encaram os atores privados [...]. Se se quer entender os Estados como atores, é preciso olhar para suas entranhas burocráticas" (1994, p. 14).

12 Ver "A Polity-Centered Analysis of American Social Provision" (Skocpol, 1992, p. 41 e ss.). Confira ainda: o termo State-centered "tem sido muitas vezes interpretado como 'determinismo burocrático', que nunca defendi. Igualmente importante, quero enfatizar que vários aspectos da política e das interações Estado/sociedade estão incluídos no meu quadro analítico de referência” (Skocpol, 1992, nota 90).

13 Cabe notar que o argumento analítico mais fino de Skocpol remonta a Lowi (1972) - diz ela: "assim como a política cria políticas públicas, também as políticas refazem a política” (Skocpol, 1992, p. 58). Interessante que, a despeito de mencionar 'capacities' e 'capabilities' em seu argumento (idem), Skocpol não aprofunda teoricamente a reflexão sobre a função desempenhada pelas capacidades na recriação de políticas. 
desprezíveis. O primeiro desses efeitos (1997, p. 27) foi o incremento e a racionalização ocorridos na capacidade do Estado norte-americano que passou por dinâmicas duradouras de inovação organizacional. Outro efeito daquelas interações foi a ampliação das formas e espaços de representação de interesses para além das tradicionais estruturas partidárias, inaugurando a "política do pluralismo" naquele país. Portanto, longe de encarnar uma espécie de natureza excepcional própria à sociedade estadunidense, o pluralismo constitui um padrão global de interação socioestatal historicamente produzido e disputado. Com e contra Skocpol (1992) e Skowronek (1982), Clemens remeteu o pluralismo à trajetória das interações concretas de um conjunto de atores e atrizes não estatais, cujas preferências e identidades foram moldadas por regras dadas, embora tenham se valido delas mesmas para transformar organizacionalmente, e em chave de representação extracongressual, a capacidade estatal daquele país.

$\mathrm{O}$ debate up to date sobre capacidades estatais se afastou da lógica inicial que marcou os neo-institucionalistas, da afirmação de que "o Estado importa" e da defesa enfática de sua autonomia. Agora, são as feições conceitual-metodológicas, bem como a superação da sinonímia entre autonomia e capacidades, ${ }^{14}$ que animam o debate. $\mathrm{O}$ objetivo de conceitualizar o que designa e distingue analiticamente a noção de capacidade estatal, além do problema de como mensurá-la, é visível em vários esforços recentes. "The state of State capacity", "Conceptualizing State capacity" " "State capacity as power: a conceptual framework", respectivamente de Kjaer et al. (2002), de Cingolani (2013), e de Lindvall e Teorell (2017),

14 Cf. "Nossa definição de capacidade estatal ajuda a esclarecer a distinção comumente borrada entre capacidade e autonomia estatais [...]. Em nossa opinião, as categorias analíticas de autonomia e capacidade precisam ser separadas. [...] $\mathrm{O}$ aparelho de Estado pode ser submetido ao mesmo critério duplo: sua autonomia reflete a medida em que não é controlado por forças externas; [já] sua capacidade reflete a medida em que ele [o aparelho] controla os resultados que tenta alcançar" (Lindvall e Teorell, 2017, p. 10; destaques no original). 
são títulos que buscam discernir condições externas e componentes internos às capacidades, situando conjuntos de fatores a elas ligados e propondo alternativas metodológicas para sua mensuração. Uma saída possível proposta para a análise de capacidades estatais é oferecida por Cingolani (2013, p. 36) que distribui seis "fatores" ou tipos de capacidade em três dimensões: (a) dimensão administrativa (tipos administrativo, comercial e de alcance territorial); (b) dimensão extrativa (taxação fiscal e de bens e serviços); e (c) dimensão de poder coercitivo (relativa ao potencial coercitivo).

Não por acaso, o debate contemporâneo ecoou na agenda brasileira e ganhou novos contornos. Em sua comparação de oito arranjos de políticas públicas, R. Pires e A. Gomide (2016) propõem a diferenciação entre capacidades técnico-administrativas e capacidades político-relacionais, de modo a testar a associação positiva entre inovação e presença destas últimas. Se não surpreende o resultado positivo por eles encontrado na correlação entre capacidade administrativa e entrega de produtos, instiga o achado segundo o qual um baixo nível de inovação está correlacionado à ausência tanto de mecanismos de participação como de presença de agentes políticos (2016, p. 138) - ambos componentes da definição de capacidade político-relacional. Além desse achado e dessa diferenciação analítica, tal proposta importa também por colocar as interações entre Estado e atores não estatais no centro da análise. Nessa mesma veia, Pereira (2014) analisou atores e fatores em jogo na construção de Belo Monte, também propondo uma diferenciação interna à noção de capacidades estatais, entre suas dimensões participativa, decisória e de coordenação interburocrática (2014, pp. 48 e ss.). Para ela, assim como para nós, "a influência de atores sociais nas decisões estatais de políticas prioritárias depende, em grande medida, não apenas da mobilização dos grupos sociais, mas das capacidades estatais" (Pereira, 2014, p. 230).

Diretamente inspirados nas inflexões do neo-institucionalismo histórico e na interlocução com a produção de Abers e 
Keck (2013), Pereira (2014), Pires e Gomide (2016) e Bichir et al. (2017), defendemos que a capacidade estatal é fator fundamental para as dinâmicas de institucionalização dos interesses e demandas dos MSs e das OSCs. Pode-se dizer que a capacidade estatal opera como uma sorte de bússola não mecânica da ação coletiva - agir com ou contra o Estado, ou agir de qualquer outro modo, leva em conta o acúmulo (ou a falta) de capacidade instalada relativamente a uma política específica na medida em que, e porque, o destino institucional duma preferência determinada também varia conforme a capacidade instalada. Por exemplo: não raro, OSCs e MSs fazem as vezes de Estado desempenhando competências e funções organizacionais, ${ }^{15}$ como nos casos de controle ou distribuição, não dominadas por agências do Executivo. Como uma espécie de guia, é a medida (acúmulo ou falta relativa) de capacidade instalada que orienta, não de forma mecânica, a ação de atores não estatais. Assim, ao mesmo tempo em que os interesses dos atores da sociedade civil são moldados, seja à distância ou diretamente, pela capacidade acumulada (ou pela falta dela) num subcampo específico de política pública, esses atores não estatais são eles próprios estruturadores de capacidades por meio das interações socioestatais.

Como vimos, a posição mesma ocupada pela capacidade estatal varia em diferentes geraçóes e casos analisados: ela designa "graus de controle" sobre o território e os recursos físicos e humanos

15 Aqui, o deslocamento operado no raciocício do segundo M. Mann (1993; 2008) nos é particularmente útil. "Poder infraestrutural é uma via de mão dupla: ele também permite a partes da sociedade civil controlar o Estado" (1993, p. 59); é, então, neste sentido de "mão dupla" que nossas interlocutoras, inspiradas em Mann, se aproximam de nosso argumento. "Se o poder infraestrutural permite ao Estado expandir seu controle sobre o território operando através de organizações não estatais, isto também abre espaço para essas organizações influenciarem o Estado" (Abers, Oliveira e Pereira, 2017, p. 859; destaque nosso). Nessa mesma linha, veja-se ainda, Bichir et al. que defendem a relevância de "considerar [na análise] a balança entre capacidades desenvolvidas pelos agentes de Estado e capacidades acumuladas por OSCs envolvidas no processo de políticas públicas" (2017, nota 5; tradução nossa). 
da população na estruturação dos Estados-Nação, assim como sua falta opera como mola propulsora de movimentos revolucionários, ao passo que ela é incrementada nos e pelos pontos de encontro com atores e atrizes não estatais, como mostraram Skocpol e Clemens. Histórica e empiricamente, as capacidades variam; já analiticamente a capacidade estatal pode e deve ser tratada como um modulador da institucionalização.

Considerar as capacidades estatais como variável fundamental dos processos sociopolíticos que pretendemos explicar pode soar uma afirmação limitada se retirada dum registro radicalmente relacional de cognição. As propostas de diferenciação analítica feitas por pesquisadores conterrâneos são bem-vindas nesse sentido porquanto inspiradoras e interlocutoras prementes de nosso raciocínio. No entanto, outras definiçõoes de state capacity, especialmente anglo-saxãs, reproduzem um tipo de raciocínio estatista que criticamos: a capacidade estatal, dizem Lindvall e Teorell (2017, p. 10), "reflete a medida em que o aparelho de Estado controla os resultados que tenta alcançar”; em chave análoga, B. Geddes (1994, p. 14) a considera como "capacidade de implementar políticas iniciadas pelo Estado”. Ora, tal como os resultados de uma política pública específica não são perseguidos e almejados apenas por atores estatais (sendo vantajosos para alguns atores sociais e desvantajosos para outros, visados e contestados por uns e por outros), também a gênese dos meios de implementação de tal ou qual política não está sobretudo, nem exclusivamente, dentro das instituições. Desde a concepção duma política pública, da sua formulação às suas execução e avaliação, o complexo dos instrumentos e modos pelos quais o Estado faz o que faz e como o faz está, antes, nas conexões de atores do Estado com atores de fora dele, mas em constante relação com ele, nomeadamente, nas interações com organizações da sociedade civil e movimentos sociais, enfim, nas interações socioestatais. Ou, como diz Pereira (2014) 
inspirada em E. Marques, esse complexo de formas de atuação e intervenção estatal se enraíza concretamente em "redes transversais" ao Estado, isto é, nas redes que aproximam ou afastam atores não estatais de atores estatais. Algo que o próprio Marques (2006) chama com argúcia de tecido do Estado e fábrica relacional do Estado.

A nosso ver, portanto, a noção de capacidades estatais merece entrar conceitualmente para o panteão dos fatores que pesam nas equações, cálculos e interações que animam movimentos sociais, seus resultados institucionais e suas análises. Sua apreensão relacional permite dizer que tende a operar em duplo nível: a capacidade estatal tanto molda as chances e estratégias de acesso e sucesso de interesses e demandas das OSCs e dos MSs, como é moldada e incrementada pela interação desses últimos atores com instituições e atores do Estado. Embora sua função concretamente desempenhada quanto às demandas civis não possa ser predita, as capacidades são parte estruturante das lógicas de institucionalização e por elas estruturadas. Incorporar as capacidades em nossos esquemas explicativos exige, em um nível, o escrutínio das capacidades acumuladas nos e pelos arranjos governamentais e institucionais de distintos naipes - ministérios, gabinetes, corpos magistrados, meios de coerção, secretarias, câmaras, assembleias, etc. -, na medida mesma em que tais capacidades não apenas pesam sobre o destino institucional das demandas de MSs e OSCs, como também moldam estas últimas. Na conta das capacidades acumuladas poderia entrar, por exemplo, a diferenciação analítica oferecida por Pires e Gomide (2016), qual seja, capacidade político-relacional. Apenas para dar um exemplo: laços - seja com representantes eleitos ou nomeados em um órgão estatal específico, com atores partidários ou com especialistas de subcampo de política pública -, poderiam ser tomados como índice de capacidade político-relacional. Tais laços constituem índice adequado, pois refletem alianças ou portas para arranjos organizacionais que 
podem facilitar ou dificultar as interações com atores civis, e tendem a aumentar ou bloquear suas chances de acesso ao Estado e à cristalização de suas demandas e interesses.

Noutro nível, por fim, importa entender se, como e em que medida as interações socioestatais, pela via das categorias de "descriçãa" do mundo e tecnologias produzidas por MSs e OSCs, incrementam a capacidade instalada. Quer dizer, importa entender também em que medida, por via de seus discursos e saberes produzidos fora e dentro de suas relações com o Estado, atores não estatais interpelam os dispositivos oficiais de intervenção, classificação e ordenamento do território e da população. Trata-se, aqui, de chegar ao outro lado das equaçóes socioestatais colocando em perspectiva a relação entre instrumentação e interação. É na instrumentação, ou seja, nos meios de concepção e execução das políticas "pretendidas" - no termo de McAdam, Tarrow e Tilly (2001) - que os atores não estatais podem ver seus interesses e categorias em jogo, pois a instrumentação é uma forma naturalizada em que opera a seletividade politicamente construída das instituições. Uma apreensão relacional dos instrumentos de políticas públicas requer a objetivação de sua gênese sociopolítica, especialmente considerando que os instrumentos, quando endógenos ao processo analisado, constituem encaixes. Para tal tarefa faz-se necessário escrutinar quais atores e condições entram em jogo, e quais demandas, interações e padrões de interação são erguidos, na incorporação e cristalização institucional de categorias e formas de intervenção que burocratas e agências governamentais, por meio e depois de interaçôes continuadas, passam a utilizar e ver como "seus", como recursos da implementação de "suas" políticas pretendidas ou, como também pode ocorrer, como de políticas "compartilhadas" com partes da sociedade civil. Jamais lineares e desafeitos a etapismos, o chamado ciclo das políticas e, em particular, os processos de implementação tendem a desnortear a maior parte dos envolvidos: militantes não cansam de apontar os limites 
de tal ou qual política pública, enquanto burocratas elogiam a "participação" e analistas normativos endossam o coro militante. A nosso ver, a entrada da análise da gênese sociopolítica dos instrumentos de políticas públicas, e sua eventual conceituação como encaixes, como parte da agenda da institucionalização de demandas dos MSs e das OSCs, é passo necessário não só à compreensão do aumento das chances de acesso ao Estado ou da sua eventual diminuição, mas também para entender as capacidades de ação do próprio Estado.

\section{Dos movimentos, políticas e processos de interação contem- plados no livro}

Entender a institucionalização de demandas e recursos de atuação dos movimentos sociais no Estado é operação analítica nada trivial, conforme mostrado mediante o diálogo crítico com a literatura disponível. Contudo, a institucionalização das agendas de reivindicações dos movimentos sociais é fenômeno dos mais notáveis do Brasil pós-transição e não apenas demanda arcabouços analíticos propícios para orientar sua compreensão cabal, mas esforços coletivos de pesquisa capazes tanto de avançar diagnósticos empíricos sobre processos de institucionalização que carecem de conhecimento sistemático quanto de moldar as distinções analíticas aqui propostas às exigências da pesquisa, contribuindo para tornar mais denso o esforço de construção de teoria. Focando o período de pós-transição democrática, os capítulos do livro apresentados a seguir abordam uma diversidade de movimentos sociais e organizações de sociedade civil no Brasil e América Latina, retratados em diferentes contextos regionais e em três níveis federativos. Não obstante essa heterogeneidade, os textos analisam sistematicamente as interações dos MSs e das OSCs com o Estado, descortinando as suas instituições em algumas políticas setoriais, bem como mostrando suas transformações. 
O leitor poderá acompanhar os processos de institucionalização de médio alcance nas interações socioestatais envolvendo o movimento negro e o movimento municipalista de saúde, ambos no nível federal e nas últimas quatro décadas, o movimento popular urbano no estado do Espírito Santo, o movimento da criança e do adolescente na política socioeducativa em São Paulo, as OSCs atuantes na política migratória no estado e cidade de São Paulo, o movimento feminista negro e as OSCs vinculadas aos Wajãpi e suas reivindicações de políticas específicas para a saúde e, especificamente, para a epidemia de HIV/Aids, o movimento feminista e sua atuação nas políticas para as mulheres no século XXI no nível nacional. Por fim, o feminismo e a incorporação da ideia de "gênero" nas políticas públicas são retratados no caso paraguaio - caso com implicações analíticas potentes para entender o processo de construção das capacidades de ação do Estado. Embora esta última análise desvie a atenção para outro caso nacional, sua inserção se justifica tanto pela riqueza da reconstrução do processo de institucionalização da agenda de gênero em contexto político-cultural especialmente adverso, como por seu potencial para pensar em perspectiva comparada os avanços e limites dos feminismos latino-americanos e das institucionalizações da noção de "gênero".

O livro é composto por duas partes que organizam o alcance empírico das nossas pesquisas. $\mathrm{Na}$ primeira, intitulada "Movimentos e políticas sociais no Brasil pós-transição", encontram-se capítulos que empregam o arsenal analítico para analisar as interações socioestatais em algumas das políticas sociais, tais como saúde, política migratória, políticas urbanas e política socioeducativa. Na segunda parte, denominada "Movimentos, raça, gênero e políticas públicas" examinam-se movimentos e políticas sociais, mas com o foco específico nos movimentos negro e feminista; as questões de raça e de gênero são aí dimensões estruturadoras de políticas públicas. 
As partes do livro podem ser exploradas separadamente ou de modo integrado, pois ambas se complementam nas contribuições para o argumento geral acerca da abordagem de encaixes institucionais e domínios de agência. A primeira parte oferece panorama de como a abordagem pode ser útil à análise de processos de institucionalização e de interação socioestatal voltados à influência na agenda política e à incidência na política pública social. Considerando diferentes movimentos, políticas sociais setoriais e níveis de governo, os capítulos dessa parte analisam em profundidade por que e como movimentos sociais constroem historicamente encaixes institucionais e domínios de agências em processos de interação socioestatal voltados à institucionalização de demandas. Ao fazê-lo, reconstroem empiricamente seu caráter processual, dinâmico, relacional, contingente e histórico. Por seu turno, a segunda parte do livro aplica a abordagem de domínios de agência a políticas públicas a partir da interseccionalidade de gênero e raça. Esse diferencial enriquece as explicaçóes seja da construção histórica de encaixes seja das configurações dos domínios de agência, seja ainda dos resultados da institucionalização nos atores e na política, pois demandas de raça e gênero tensionam noções universalistas presentes na edificação de parte das políticas setoriais de caráter social.

Abrindo a primeira parte do livro, o capítulo de autoria de Monika Dowbor parte de questão desafiante para os movimentos sociais. As reivindicaçóes e os projetos de movimentos sociais, mesmo quando transformados em políticas públicas, nunca estão totalmente seguros contra as mudanças colocadas pelo jogo eleitoral democrático, isto é, pela alternância no poder. A pergunta a ser respondida é, então, como os movimentos sociais se protegem contra as incertezas dos resultados eleitorais? O caso analisado é o Movimento Municipalista de Saúde (1975-2010) e a hipótese oferecida como resposta é: para fugir dessas incertezas (normais em cenários de revezamento poliárquico) os movimentos sociais bus- 
cam acessos institucionalizados ao Estado e constroem novas instituições de modo a garantir maior permanência e estabilidade nos processos decisórios. Ou, em nossos termos, buscam criar os encaixes e configuração de encaixes. Durante a transição democrática, o movimento municipalista constituiu uma associação de representação em nível federativo para poder reivindicar acesso à instância de planejamento no nível nacional. Após a promulgação da Constituição garantiu sua presença no novo Conselho Nacional da Saúde e, em seguida, propôs a criação de novas instituições, a saber, as Comissões Bipartite e Tripartite voltadas exclusivamente para a implementação da municipalização de serviços de saúde, a principal pauta do movimento. Em 2011, os atores do movimento elevaram o grau de sua influência ao inscrever sua institucionalização na Lei Orgânica de Saúde: garantiram à sua organização o estatuto de utilidade pública e de entidade representativa dos entes municipais e tornaram as Comissões Bipartite e Tripartite foros de negociação e pactuação entre gestores quanto aos aspectos operacionais do Sistema Único de Saúde. Os efeitos dessa institucionalização para o movimento social apontam para a transformação desse tipo de ação coletiva em outro tipo de ação, mas não para a desmobilização tout court.

O capítulo de Patrícia Tavares de Freitas foca a imigração boliviana e oferece diagnóstico instigante das transformações ocorridas na governança da política migratória no estado e cidade de São Paulo à luz da recomposição da imigração, da emergência de novos atores coletivos e da disputa partidária entre os principais contendentes da pós-transição em São Paulo, a saber, o Partido da Social Democracia Brasileira (PSDB) e o Partido dos Trabalhadores (PT). O campo da política migratória herdado da ditadura obedecia à lógica da segurança nacional e não dizia respeito ao principal contingente da imigração, oriundo do Nordeste. A nova imigração internacional, no caso, a imigração boliviana, acabou por reconfigurar um campo em que autoridades migratórias 
e de políticas sociais, bem como atores sociais das esferas civil e religiosa, tradicionalmente vinculados à assistência da população nordestina, foram interpelados pelas demandas desse novo ator urbano: o novo imigrante. A contribuição do capítulo ao livro é reconstruir de modo pioneiro, mediante a análise de três ciclos de interações socioestatais, a emergência de um domínio de agência de configuração dual de caráter societal-partidário, em que a institucionalização das demandas e os encaixes produzidos orbitam em torno de dois polos que ordenam, diferenciam e alinham ao PSDB e ao PT concepções diferentes das políticas, distintos órgãos da administração pública estadual e municipal, OSCs e entidades religiosas, associações de imigrantes e diversos lugares de circulação dos imigrantes na cidade.

Euzeneia Carlos, em seu capítulo, analisa o processo histórico de construção de encaixes institucionais e domínio de agência pelo movimento popular urbano, no Espírito Santo, um caso emblemático do processo de institucionalização de demandas e ações no Brasil pós-transição. Por meio de análise histórica longitudinal do movimento social, ao longo de três décadas (1980-2010), a autora reconstrói os processos de interação socioestatal a partir de fatores endógenos, donde derivam os encaixes com vistas a influenciar a agenda pública. O capítulo contribui duplamente com a proposta analítica do livro. Primeiro, ao identificar dois mecanismos na formação de encaixes e domínio de agência que tensionam a ideia de autonomia dos movimentos como ausência de relação com as instituições, quais sejam: (a) a relação com "incubadoras institucionais" na fundação do movimento e sua função no aprendizado e capacidades do ator, e (b) as alianças do movimento com coalizões partidárias nas eleições municipais e o papel dessas na permeabilidade do Estado. Segundo, ao analisar o perfil configuracional do domínio de agência forjado pelo movimento popular, composto além dos encaixes por capacidades organizacionais e interações socioestatais. O capítulo demonstra que organizações reli- 
giosas e partidos políticos de esquerda atuaram como incubadoras para o movimento contencioso, cujas relações pregressas geraram aprendizados e habilidades no ator para criar encaixes no Estado. Argumenta que um conjunto de encaixes, capacidades organizacionais e interações cooperativas configuram o domínio de agência do movimento popular, que prolonga no tempo sua influência política dada a exclusividade de acesso ao Estado e a legitimidade de agir em políticas específicas.

Enfatizando o processo de constituição mútua entre sociedade civil e Estado, o capítulo de Maria do Carmo Albuquerque analisa os resultados do movimento da criança e do adolescente na política socioeducativa. Por meio do exame de ciclos de mobilização do movimento, a autora inquire sobre sua incidência nas mudanças institucionais voltadas ao "paradigma garantista" na elaboração e implementação da política socioeducativa, no município de São Paulo. O capítulo oferece importante contribuição ao livro ao analisar as "coalizóes de defesa" do paradigma garantista e seu sistema de crenças compartilhadas entre atores da sociedade civil e da sociedade política, especialmente seu papel na formação de encaixes institucionais com capacidade de incidência na política socioeducativa

$\mathrm{Na}$ segunda parte do livro, Flavia Rios analisa o processo de institucionalização do movimento negro brasileiro que, nas quatro últimas décadas, assume um duplo sentido: seja a institucionalização no movimento social mediante transformações em sua estrutura organizacional, seja a institucionalização na esfera do Estado por meio da construção de encaixes institucionais e de seus resultados em termos de incorporação da agenda societal. Seu capítulo oferece contribuição singular ao livro ao identificar nesse processo de institucionalização os encaixes institucionais que lograram resultados à inclusão da igualdade racial na agenda política. A autora sustenta que a dinâmica de interação do ativismo negro com as esferas executiva e burocrática do Estado, mediada 
por encaixes institucionais, assume relevo na explicação da institucionalização da agenda da igualdade racial no Brasil. Concernente à abordagem do livro, o capítulo aponta os encaixes enquanto um tipo de solidificação institucional que amplia a capacidade de influência dos atores, o qual requer certo padrão de complexificação organizacional do ator e de permeabilidade do Estado.

Em "Feminismos, movimentos de mulheres e as políticas de saúde para as mulheres", Layla Carvalho oferece uma rica análise de três articuladores civis em suas relações com a Política Nacional de Atenção Integral à Saúde da Mulher e o Programa Rede Cegonha. No caso específico, são analisadas as interações da Rede Feminista de Saúde, da Articulação de Mulheres Negras Brasileiras e da Rede pela Humanização do Parto e Nascimento com aquelas duas políticas do Ministério da Saúde. Vistos por lentes relacionais, os padrões de interação, mais ou menos próximos, mais ou menos cooperativos, de cada uma dessas redes vis-á-vis as políticas de saúde tendem a variar conforme os encaixes institucionais forjados com base na capacidade de ação e interpelação daquelas redes. Mais ainda: a variabilidade aí observada por Carvalho, especialmente no jogo de aproximações e distanciamentos entre atrizes civis e estatais, lança luz clarividente sobre a complexidade das dinâmicas e lógicas socioestatais. $\mathrm{O}$ leque de disputas e alianças arquitetadas ao redor de encaixes nas políticas públicas e seus instrumentos desautoriza qualquer simplificação teórica, demandando plasticidade e alcance analíticos adequados aos limites institucionais e aos liames sociopolíticos nos quais são forjadas percepções nativas (civis e estatais) tanto do que determinada política pública é, como daquilo que ela pode ou deveria ser.

Amiúde, a institucionalização de demandas de OSCs e MSs em uma determinada área de políticas é descrita em registro positivo pela literatura devido a seus efeitos de inclusão. Padrões de inclusão universalistas, como aqueles construídos no setor saúde pelo movimento pela reforma sanitária, todavia, podem obs- 
tar demandas de inclusão formuladas por grupos historicamente marginalizados. O capítulo de Vera Schattan Coelho e Adrian Gurza Lavalle se debruça sobre o movimento negro, com especial atenção para o movimento feminista negro, e sobre o trabalho de OSCs vinculadas aos Wajãpi, examinando, precisamente, a vocalização de suas demandas em relação ao sistema de saúde e à difícil recepção e absorção das mesmas por autoridades e profissionais de saúde habituados à linguagem técnica, a evidências estatísticas e princípios de atenção de índole universalista. Tais dificuldades acentuaram-se quando as demandas dos movimentos negro e indígena reivindicaram políticas específicas para a epidemia de HIV/ Aids. Mais: os próprios atores sociais tiveram que desenvolver repertórios discursivos para exigir políticas específicas em termos assimiláveis para os gestores da política setorial. A contribuição do capítulo ao livro é mostrar que tanto a formulação como a recepção de demandas são capacidades e, enquanto tais, não surgem espontaneamente, nem emergem de modo imediato da vontade dos atores, mas são produzidas ou, melhor, politicamente construídas ao longo do tempo por processos de interação socioestatal de resultados variáveis quanto aos níveis de institucionalização. No caso do movimento negro, esses processos levaram à edificação de um domínio de agência chamado de campo da saúde da população negra e à definição de políticas específicas para lidar com o $\mathrm{HIV} / \mathrm{Aids}$; já no caso do movimento indígena, sedimentara-se um subsistema de saúde de alcance mais modesto e pouco progresso houve no desenvolvimento de políticas de HIV/Aids capazes de funcionar porque consoantes à visão de mundo indígena.

Fechando o volume, José Szwako e Renato Perissinotto propõem um diálogo com a chamada "virada ideacional" ocorrida na literatura sobre políticas públicas como uma alternativa teórico-analítica adequada para aqueles que, como nós, querem deslindar variáveis e dimensões implicadas nas dinâmicas de institucionalização de demandas de movimentos sociais. 
Este capítulo reconstrói, primeiramente, a trajetória intelectual da ideia de 'gênero' forjada por redes, organizações e militantes do feminismo paraguaio, para em seguida observar como essa ideia foi incorporada e institucionalizada em duas políticas, quais sejam, a política de saúde sexual e reprodutiva, bem como a política de combate à violência contra a mulher. De olho nas interações socioestatais implicadas nos casos de institucionalização do componente de 'gênero', os autores sugerem a noção de capacidade cognitiva como uma dimensão interna às capacidades estatais heuristicamente fértil para a compreensão das formas pelas quais os movimentos sociais podem ter seus projetos e ideais transformados em instituições.

\section{REFERÊNCIAS}

ABERS, Rebecca; KECK, Margaret. Practical Authority: Agency and Institutional Change in Brazilian Water Politics. Oxford: Oxford University Press, 2013.

ABERS, Rebecca; OLIVEIRA, Marilia S.; PEREIRA, Ana. K. Inclusive Development and the Asymmetric State: Big Projects and Local Communities in the Brazilian Amazon. The Journal of Development Studies, 2017, v. 53, n. 6, pp. $857-872$.

ABERS, Rebecca; SERAFIM, Liza; TATAGIBA, Luciana. Repertórios de interação Estado-sociedade em um Estado heterogêneo: a experiência na era Lula. Dados, 2014, v. 57, n. 2, pp. 325-357. Disponível em: <http://dx.doi. org/10.1590/0011-5258201411>.

ABERS, Rebecca; VON BÜLOW, Marisa. Movimentos sociais na teoria e na prática: como estudar o ativismo através da fronteira entre Estado e sociedade? Sociologias, 2011, n.28, pp.52-84. Disponível em: <http://dx.doi.org/10.1590/ S1517-45222011000300004>.

ALMEIDA, Débora R. Representação além das eleições: repensando as fronteiras entre Estado e sociedade. Jundiaí: Paco Editorial, 2015. 
ALONSO, Angela; COSTA, Valeriano; MACIEL, Débora. Identidade e estratégia na formação do movimento ambientalista brasileiro. Novos Estudos Cebrap, 2007, v. 79, pp. 151-167.

AMENTA, Edwin et al. Challengers and States: Toward a Political Sociology of Social Movements. Sociological Views on Political Participation, 2002, v. 10, pp.47-83.

AMENTA, Edwin et al. Age for Leisure? Political Mediation and the Impact of the Pension Movement on US Old Age Policy. American Sociological Review, 2005 , v. 70 , pp. $516-538$.

AMENTA, Edwin et al. The Political Consequences of Social Movements. Annual Review of Sociology, 2010, v. 36, pp. 287-307.

ARDITI, Benjamin. El devenir-otro de la política: un archipiélago post-liberal. In: Arditi, Benjamin (Ed.) ¿Democracia post-liberal? El espacio político de las asociaciones. México: Anthropos/UNAM, 2005, pp. 219-248.

BANASZAK, Lee A. Inside and Outside the State: Movement Insider Status, Tactics, and Public Policy Achievements. In: Meyer, David et al. (Ed.) Routing the Opposition: Social Movements, Public Policy, and Democracy. Minneapolis: University of Minnesota Press, 2005, pp. 149-176.

BICHIR, Renata; BRETTAS, Gabriela; CANATO, Pamela. Multi-level Governance in Federal Contexts: the Social Assistance Policy in the City of São Paulo. Brazilian Political Science Review, 2017, v. 11, n. 2, e0003. Epub July 27.

BOSCHI, Renato. Corporativismo societal, a democratização do Estado e as bases social-democratas do capitalismo brasileiro. Insight Inteligência, 2010, v. 48, pp. 1-20.

BROWNE, William P. Organized Interests and their Issue Niches: A Search for Pluralism in a Policy Domain. The Journal of Politics, 1990, v. 52, n. 2.

CARLOS, Euzeneia. Movimentos sociais e instituições participativas: efeitos organizacionais, relacionais e discursivos. Tese (Doutorado em Ciência Política) - Universidade de São Paulo, São Paulo, 2012.

CARLOS, Euzeneia. Movimentos sociais e instituiçôes participativas: efeitos do engajamento institucional no contexto pós-transição. Belo Horizonte: Fino Traço, 2015. 
CARLOS, Euzeneia; DOWBOR, Monika; ALBUQUERQUE, Maria do C. Movimentos sociais e seus efeitos nas políticas públicas: balanço do debate e proposições analíticas. Civitas, 2017, v. 17, n. 2, pp. 360-378.

CHAMBRÉ, Susan; FATT, Naomi. Beyond the Liability of Newness: Nonprofit Organizations in an Emerging Policy Domain. Nonprofit and Voluntary Sector 2uarterly, 2002, v. 31.

CHARTOCK, Sarah. Corporatism with Adjectives? Conceptualizing Civil Society Incorporation and Indigenous Participation in Latin America, Latin American Politics and Society, 2013, v. 55, n. 2, pp. 52-76.

CINGOLANI, Luciana. The State of State Capacity: A review of Concepts, Evidence and Measures. UNU-Merit Working Paper Series on Institutions and Economic Growth, 2013. IPD WP13.

CLEMENS, Elizabeth. Organizational Repertoires and Institutional Change: Women's Groups and the Transformation of US Politics, 1890-1920. American Journal of Sociology, 1993, v. 98, n. 4.

CLEMENS, Elizabeth. The People's Lobby. Organizational Innovation and the Rise of Interest Group Politics in the United States, 1890-1925. Chicago: Chicago University Press, 1997.

CLEMENS, Elizabeth. Two Kinds of Stuff: The Current Encounter of Social Movements and Organizations. In: Davis, Gerald et al. (Ed.) Social Movements and Organization Theory. Cambridge: Cambridge University Press, 2005, pp.351-365.

COLLIER, Ruth; HANDLIN, Samuel (Ed.) Reorganizing Popular Politics: Participation and the New Interest Regime in Latin America. University Park, PA: Pennsylvania State University Press, 2009.

DAGNINO, Evelina. Civil Society in Latin America. In: Edwards, Michael (Ed.) The Oxford Handbook of Civil Society. Oxford: Oxford University Press, 2011.

DAHL, Robert. Who Governs?: Democracy and Power in an American City. New Haven: Yale University Press, 1961.

DAHL, Robert. Um prefácio à teoria democrática. Rio de Janeiro: Jorge Zahar, 1989. 
DAHL, Robert. Los dilemas del pluralismo democrático. Autonomia versus control. México: Alianza Editorial/Conaculta, 1991.

DAHL, Robert. Poliarquia: participação e oposição. São Paulo: EdUSP, 1997.

DIANI, Mario. Networks and social movements: a research programme. In: Diani, Mario; McAdam, Doug (Eds) Social Movements and networks. Relational approaches to collective action. Oxford University Press, 2003, pp. 298-319.

DOWBOR, Monika. A arte da institucionalização: estratégias de mobilização dos sanitaristas (1974-2006). Tese (Doutorado em Ciência Política) Universidade de São Paulo, São Paulo, 2012. Disponível em: <http://dx.doi. org/10.11606/T.8.2012.tde-06032013-111003>.

EVANS, Peter. Embedded Autonomy: States and Industrial Transformation. Princeton, NJ: Princeton University Press, 1995.

GEDDES, Barbara. Politician's Dilemma: Building State Capacity in Latin America. Berkeley: University of California Press, 1994.

GOLDSTONE, Jack. Bridging Institucionalized and Noninstitucionalized Politics. In: States, Parties, and Social Movements. Cambridge: Cambridge University Press, 2003.

GOODWIN, Jeff. Revolutions and Revolutionary Movements. In: Janoski, Thomas et al. (Ed.). The Handbook of Political Sociology: States, Civil Societies, and Globalization. Cambridge: Cambridge University Press, 2003.

GURZA LAVALLE, Adrian. Crítica ao modelo da nova sociedade civil. Lua Nova, 1999, v. 47, pp.121-135.

GURZA LAVAlle, Adrian; ACHARYA, Arnab; HOUTZAGER, Peter. Beyond comparative anecdotalism: lessons on civil society and participation from São Paulo, Brazil. World Development, 2005, v. 33, n. 6, pp. 951-964.

GURZA LAVALLE, Adrian; HOUTZAGER, Peter; CASTELLO, Graziela. Representação política e organizações civis: novas instâncias de mediação e os desafios da legitimidade. Revista Brasileira de Ciências Sociais, 2006a, v. 21, n. 60, pp.43-66.

GURZA LAVALLE, Adrian; HOUTZAGER, Peter; CASTELLO, Graziela. Democracia, pluralização da representação e sociedade civil. Lua Nova, 2006b, v. 67, pp.49-103. 
GURZA LAVALLE, Adrian; HOUTZAGER, Peter; CASTELLO, Graziela. A construção política das sociedades civis. In: Gurza Lavalle, Adrian (Ed.). $O$ horizonte da politica: questões emergentes e agendas de pesquisa. São Paulo: EdUnesp/Cebrap/CEM, 2012, pp. 185-259.

GURZA LAVALLE, Adrian; ISUNZA, Ernesto. A trama da crítica democrática: da participação à representação e à accountability. Lua Nova, 2011, v. 84, pp. 95-140.

GURZA LAVALLE, Adrian; SZWAKO, José. Sociedade civil, Estado e autonomia: argumentos, contra-argumentos e avanços no debate. Opinião Pública, 2015 , v. 21, n. 1, pp. 157-187.

GUTIERRES, Kellen A. Projetos politicos, trajetórias e estratégias: a politica de assistência social entre o partido e o Estado. Tese (Doutorado em Ciências Sociais) - Universidade Estadual de Campinas, Campinas, 2015.

HANAGAN, Michael. Social Movements, Incorporation, Disengagement, and Opportunities - a Long View. In: Giugni, Marco; McAdam, Doug; Tilly, Charles (Ed.) From Contention to Democracy. Lanham, MA: Rowman and Littlefield, 1998.

HOUTZAGER, Peter. Os últimos cidadãos: conflito e modernização no Brasil rural (1964-1995). São Paulo: Globo, 2004.

HOUTZAGER, Peter; GURZA LAVALlE, Adrian; ACHARYA, Arnab. Atores da sociedade civil e atores políticos: participação nas novas políticas democráticas em São Paulo. In: Avritzer, Leonardo (Org.). A participação em São Paulo. São Paulo: EdUnesp, 2004.

HOUTZAGER, Peter; KURTZ, Marcus. The Institutional Roots of Popular Mobilization: Transformation and Rural Politics in Brazil and Chile, 1960-95. Comparative Studies in Society and History, 2000, v. 42, n. 2, pp. 394-424.

KINGDON, John. Agendas, Alternatives, and Public Policies. New York: Harper Collins, 1995.

KJAER, Anne Mette et al. Conceptualizing State Capacity. Democracy, the State, and Administrative Reforms. Demstar Research Report, n. 6, University of Aarhus, 2002.

KNOKE, David. Networks of Elite Structure and Decision Making. Sociological Methods and Research, 1993, v. 22, n. 1. 
KNOKE, David. Comparing Policy Networks: Labor Politics in the US, Germany, and Japan. Cambridge: Cambridge University Press, 1996.

KRIESI, Hans P. La estructura organizacional de los nuevos movimientos sociales en su contexto político. In: McAdam, Doug; McCarthy, John; Zald, Mayer (Ed.). Movimientos sociales: perspectivas comparadas. Madrid: Istmo, 1999, pp. 221-261.

LASCOUMES, Pierre; LE GALÈS, Patrick. Introduction: Understanding Public Policy through its Instruments. Governance: An International Journal of Policy, Administration, and Institutions, 2007, v. 20, n. 1, pp. 1-21.

LINDVALL, Johannes; TEORELL, Jan. State Capacity as Power: A Conceptual Framework. 2017. Disponível em: <https://projects.iq.harvard.edu/files/ pegroup/files/lindvallteorell2017_updated.pdf>.

LOWI, Theodore. Four Systems of Policy, Politics, and Choice. Public Administration Review, 1972, v. 32, n. 4, pp. 298-310.

MAHONEY, James. Nominal, Ordinal, and Narrative Appraisal in Macrocausal Analysis. The American Journal of Sociology, 1999, v. 104, n. 4, pp. 1154-1196.

MAHONEY, James. Path Dependence in Historical Sociology. Theory and Society, 2000, v. 29, n. 4, pp. 507-548.

MANLEY, John. Neo-pluralism: A class analysis of pluralism I and pluralism II. American Political Science Review, 1983, v. 77, n. 2.

MANN, Michael. The Autonomous Power of the State: Its Origins, Mechanisms and Results. Archives Européenne de Sociologie, 1984, v. 25, pp. 185-213.

MANN, Michael. The Sources of Social Power: The Rise of Classes and NationStates, 1760-1914. v. 2. New York: Cambridge University Press, 1993.

MANN, Michael. Infrastructural Power Revisited. Studies in Comparative International Development, 2008, v. 43, pp. 355-365, Doi:10.1007/s12116008-9027-7.

MARCH, James; OLSEN, Johan. The New Institutionalism: Organizational Factors in Political Life. American Political Science Review, 1984, v. 78, pp. 734-759. 
MARQUES, Eduardo C. Notas críticas a literatura sobre Estado, políticas estatais e atores políticos. BIB: Revista Brasileira de Informação Bibliográfica em Ciências Sociais, 1997, v. 43.

MARQUES, Eduardo C. Redes sociais e poder no Estado brasileiro: aprendizados a partir de políticas urbanas. Revista Brasileira de Ciências Sociais, 2006 , v. 21 , n. 60 , pp. 15-41.

MCADAM, Doug; SCOTT, R. Organizations and Movements. In: Davis, Gerald F. et al. (Ed.). Social Movements and Organization Theory. Cambridge: Cambridge University Press, 2005.

MCADAM, Doug; TARROW, Sidney; TILlY, Charles. Dynamics of Contention. Cambridge: Cambridge University Press, 2001.

MCCARTHY, John; ZALD, Mayer. The Trends of Social Movements in America: Professionalization and Resource Mobilization. Morristown, NJ: General Learning Press, 1973.

MCNULTY, Stephanie. Participatory Democracy? Exploring Peru's Effort to Engage Civil Society in Local Governance. Latin America Politics and Society, 2013, v. 55, n. 3, pp. 69-92.

MEYER, David S.; TARROW, Sidney (Ed.). The Social Movement Society: Contentions Politics for a New Century. Lanham, MA: Rowman and Littlefield, 1998.

NETTL, J. P. The State as a Conceptual Variable. World Politics, 1968, v. 20, n. 4, pp. 559-592.

OFFE, Claus. Capitalismo desorganizado. São Paulo: Brasiliense, 1998.

PEREIRA, Ana K. A construção de capacidade estatal por redes transversais: o caso de Belo Monte. Tese (Doutorado em Ciência Política) - Universidade de Brasília, Brasília, 2014.

PIRES, Roberto; GOMIDE, Alexandre. Governança e capacidades estatais: uma análise comparativa de programas federais. Revista Sociologia e Política, 2016, v. 24, n. 58, pp. 121-143.

PIVEN, Frances F.; CLOWARD, Richard. Poor People's Movements: Why They Succeed, How They Fail. New York: Vintage Books, 1979. 
SABATIER, Paul. The Need for Better Theories. In: Sabatier, Paul (Ed.). Theories of Policies Process. Boulder, CO: Westview Press, 2007, pp. 3-20.

SABATIER, Paul; WEIBLE, Christopher. The Advocacy Coalition Framework: Innovations and Clarifications. In: Sabatier, Paul (Ed.). Theories of Policies Process. Boulder, CO: Westview Press, 2007, pp. 189-222.

SALISBURY, Robert; HEINZ, John; LAUMANN, Edward; NELSON, Robert. Who Works with Whom? Interest Group Alliances and Opposition. The American Political Science Review, 1987, v. 81, n. 4.

SCHLOSBERG, David Resurrecting the Pluralist Universe. Research Quarterly, 1998, v. 51, n. 3, pp. 583-561.

SCHMITTER, Philipe. Still the Century of Corporatism? Review of Politics, 1974, n. 36, pp. 85-131.

SCHMITTER, Philipe. The Consolidation of Democracy and Representation of Social Groups, American Behavioral Scientist, 1992, v. 35, n. 4-5, pp. 422-449.

SCHMITTER, Philipe. Some Propositions about Civil Society and the Consolidation of Democracy. Wien: Institut für Höhere Studien, 1993.

SCHMITTER, Philipe. Un posible esbozo de una democracia 'post-liberal'. In: Arditi, Benjamin (Ed.). ¿Democracia post-liberal? El espacio politico de las asociaciones. México: Anthropos/UNAM, 2005, pp. 249-263.

SILVA, Marcelo K.; OLIVEIRA, Gerson. A face oculta(da) dos movimentos sociais: trânsito institucional e intersecção Estado-Movimento: uma análise do Movimento de Economia Solidária no Rio Grande do Sul. Sociologias, 2011, ano 13, n. 28, pp. 86-124.

SKOCPOL, Theda. States and Social Revolutions: A Comparative Analysis of France, Russia, and China. Cambridge, UK: Cambridge University Press, 1979.

SKOCPOL, Theda. Bringing the State Back In: Strategies of Analysis in Current Research. In: Evans, Peter; Rueschemeyer, Dietrich; Skocpol, Theda (Ed.). Bringing the State Back In. Cambridge, UK: Cambridge University Press, 1985.

SKOCPOL, Theda. Protecting Soldiers and Mothers: The Political Origins of Social Policy in the United States. Cambridge, MA: Harvard University Press, 1992. 
SKOCPOL, Theda. Why I Am an Historical Institutionalist. Polity, 1995, v. 28, n. 1, pp. 103-106.

SKOCPOL, Theda. Diminished Democracy. From Membership to Management in American Civic Life. Norman, OK: University of Oklahoma Press, 2003.

SKOCPOL, Theda. Bringing the State Back In: Retrospect and Prospect. The 2007 Johan Skytte Prize Lecture. Scandinavian Political Studies, 2008, v. 31, n. 2, pp. 109-124.

SKOCPOL, Theda; CROWLEY, J. E. The Rush to Organize: Explaining Associational Formation in the United States, 1860s-1920s. American Journal of Political Science, 2001, v. 45, n. 4, pp. 813-829.

SKOWRONEK, Stephen. Building a New American State: The Expansion of National Administrative Capacities, 1877-1920. Cambridge, UK: Cambridge University Press, 1982.

SZWAKO, José. 'Del otro lado de la vereda': luta feminista e construção democrática no Paraguai pós-ditatorial. Tese (Doutorado em Ciências Sociais) - Universidade Estadual de Campinas, Campinas, 2012.

SZWAKO, José. Incorporação estatal e reprodução institucional: ou como observar os efeitos institucionais da ação coletiva. In: Congresso Internacional da Latin American Studies Association (LASA), 31., 2013, Washington, DC. 2013.

TARROW, Sidney. El poder en movimiento: los movimientos sociales, la acción colectiva y la politica. Madri: Alianza, 1997.

TATAGIBA, Luciana; BLIKSTAD, Karin. Como se fosse uma eleição para vereador: dinâmicas participativas e disputas partidárias na cidade de São Paulo. Lua Nova, 2011, n. 84, pp. 175-217.

TILLY, Charles. Reflections on the History of European State-Making. In: Tilly, Charles (Ed.). The Formation of National States in Western Europe. Cambridge, MA: Harvard University Press, 1975, pp. 3-83.

TILLY, Charles. Coerção, capital e estados europeus. São Paulo: EdUSP, 1996.

TILLY, Charles. Mechanisms in Political Processes. Annual Review of Political Science, 2001, v. 4, pp. 21-41. 
TILLY, Charles. The Politics of Collective Violence. Cambridge, UK: Cambridge University Press, 2003.

TILLY, Charles; TARROW, Sidney (2007), Contentious Politics. Boulder, CO: Paradigm Publishers, 2007.

TRUMAN, David. The Governamental Process: Political Interest and Public Opinion. Westport, CT: Greenwood Press, 1951.

VITE, Francisco. Offe, Schmitter y la institucionalización de un segundo circuito de la política. In: Arditi, Benjamín (Ed.). ¿Democracia post-liberal? El espacio político de las asociaciones. México: Anthropos/UNAM, 2005, pp. $145-172$.

ZAREMBERG, Gisela; GURZA LAVALLE, Adrian; GUARNEROS-MESA, Valeria. Beyond Elections: Representation Circuits and Political Intermediation. In: Zaremberg, Gisela et al. (Ed.). Intermediation and Representation in Latin America: Actors and Roles Beyond Elections. London: Palgrave Macmillan, 2017, pp. 1-30. 